\title{
Topographic Rossby Waves at Two Different Periods in the Northwest Pacific Basin
}

\author{
Masatoshi Miyamoto, Eitarou OKa, Daigo Yanagimoto, Shinzou Fujio, and Maki Nagasawa \\ Atmosphere and Ocean Research Institute, The University of Tokyo, Kashiwa, Japan \\ Genta Mizuta \\ Graduate School of Environmental Earth Science, Hokkaido University, Sapporo, Japan \\ SHIRO IMAWAKI ${ }^{\mathrm{a}}$ \\ Kyushu University, Yokohama, Japan \\ MASAO KUROGI \\ Information Engineering Program, Research Institute for Value-Added-Information Generation, Japan Agency for \\ Marine-Earth Science and Technology, Yokohama, Japan \\ Hiroyasu Hasumi \\ Atmosphere and Ocean Research Institute, The University of Tokyo, Kashiwa, Japan
}

(Manuscript received 15 December 2019, in final form 30 June 2020)

\begin{abstract}
To clarify characteristics and mechanisms of mesoscale variability in the deep ocean, we conducted a twodimensional observation with a $3 \times 3$ grid mooring array around site $\mathrm{R}\left(30^{\circ} \mathrm{N}, 147^{\circ} \mathrm{E}\right)$ during $2014-16$. We analyze the obtained velocity data together with past mooring observation data in the northwest Pacific basin and outputs of an ocean general circulation model (OGCM). In our two-dimensional mooring observations, the variability of zonal and meridional velocities at a depth of $4000 \mathrm{~m}$ was prominent at periods of 174 and 58 days, respectively. The variability at periods of 174 and 58 days propagated to the northwest and west-southwest, respectively, as a single plane wave. The variability at the period of 58 days was considered to be topographic Rossby waves (TRWs) under stratification originated in the Kuroshio Extension region north of site R, as demonstrated by our previous study. At the period of 174 days, zonal and meridional wavenumbers estimated from the phase lag for zonal velocities also satisfied the dispersion relation of TRWs under stratification. Backward ray tracing from site R indicated that energy of TRWs propagated from the eastern slope of the Shatsky Rise to site $\mathrm{R}$ almost along $f / H$ contours, where $f$ is the Coriolis parameter and $H$ is water depth. The orientation of major axis of variance ellipses at periods of 174 days and longer, obtained from the past mooring observations and the OGCM outputs, tended to be parallel to $f / H$ contours, being consistent with the direction of energy propagation of TRWs.
\end{abstract}

KEYWORDS: Bottom currents; Eddies; Mesoscale processes; Rossby waves; Waves, oceanic

\section{Introduction}

Mesoscale variability exists almost ubiquitously from the surface to abyssal layers of the global ocean (Robinson 1983). Its typical horizontal scales of $100-300 \mathrm{~km}$ and temporal scales of a week to several months were clarified by intensive conductivity-temperature-depth (CTD), mooring, and float observations in the 1970s and 1980s, particularly in the western North Atlantic under the Mid-Ocean Dynamics Experiment (MODE; MODE Group 1978) and the Polygon MODE (POLYMODE; Price and Rossby 1982; Grachev et al. 1984). Mesoscale variability from the surface to abyssal layers at periods of 53,77,129, and 161 days (187 and 332 days), detected by moorings in the MODE site in the

\section{${ }^{\mathrm{a}}$ Emeritus.}

Corresponding author: Masatoshi Miyamoto,mmiyamoto45845@ gmail.com eastern Hatteras Abyssal Plain and the western Bermuda Rise, was considered to be barotropic planetary Rossby waves (baroclinic planetary Rossby waves) without considering influence of bottom topography (McWilliams and Flierl 1976). Mesoscale variability at a period of 61 days, observed by sound fixing and ranging (SOFAR) floats at a depth of $1300 \mathrm{~m}$ around the POLYMODE Local Dynamics Experiment site located to the north of the MODE site, was considered to be barotropic topographic Rossby waves (TRWs) without considering influence of stratification (Price and Rossby 1982).

Since the launch of the TOPEX/Poseidon satellite altimeter in fall 1992, mesoscale variability in the surface layer has been monitored globally with a temporal resolution of 10 days (Ducet et al. 2000), and was considered to be mainly baroclinic planetary Rossby waves, based on its westward phase speed (Chelton and Schlax 1996) and nonlinear mesoscale eddies (Chelton et al. 2011). Such surface mesoscale variability transports heat and dissolved materials in the 
global ocean, with amounts comparable to those by largescale circulation (e.g., Roemmich and Gilson 2001; Dong et al. 2014; Zhang et al. 2014). On the other hand, deep mesoscale variability, which cannot be detected by satellite altimeter, has continued to be investigated by mooring observations, especially in the western boundary region such as trenches and continental slopes/rises where deep western boundary currents (DWBCs) have been considered to transport deep water (Stommel 1958; Stommel and Arons 1960a,b). Deep mesoscale variability at various periods of 7-100 days has been observed on sloping bottom topography in the western North Atlantic and the Gulf of Mexico, and has been judged to be TRWs with bottom intensified variability (Rhines 1970), based on the dispersion relation and the vertical structure with assumption of vertically constant stratification near the bottom (e.g., Thompson and Luyten 1976; Pickart and Watts 1990; Hogg 2000; Hamilton 2009). These TRWs were considered to be generated in the Gulf Stream and Loop Current regions and propagate shoreward under the influence of steep bottom topography (Bower and Hogg 1992; Pickart 1995; Oey and Lee 2002), as reproduced by theoretical and idealized models (MalanotteRizzoli et al. 1995).

Recently, trajectories of 55 RAFOS floats (SOFAR spelled backward; Rossby et al. 1986) deployed around $50^{\circ} \mathrm{N}, 49^{\circ} \mathrm{W}$ in DWBCs suggested that not only DWBCs but also flow in interior regions transports deep water from the subpolar region to the subtropical region of the North Atlantic (e.g., Bower et al. 2009, 2011). A comparison of ocean general circulation model (OGCM) outputs among eddy-resolving, eddy-permitting, and non-eddy-permitting resolutions indicated that such interior flow is driven by mesoscale variability (Gary et al. 2011). However, characteristics, mechanism, and energy propagation of deep mesoscale variability in interior regions are still unclear due to paucity of mooring observations compared to western boundary regions.

Deep mesoscale variability has also been observed by moorings in the North Pacific. It was strong and highly coherent with surface mesoscale variability in the Kuroshio Extension region (Schmitz 1988; Greene et al. 2012), which suggested that the deep mesoscale variability was generated in this region. In the interior region south of the Kuroshio Extension, deep mesoscale variability was explored from late 1970 s to mid-1980s around site R $\left(30^{\circ} \mathrm{N}\right.$, $147^{\circ}$ E; Fig. 1a; Imawaki 1983, 1985; Imawaki and Takano 1982, 2018; Miyamoto et al. 2017). In the first mooring observation from October 1978 to March 1979, mesoscale variability of zonal and meridional velocities $(u$ and $v$ ) at periods of 44 and 97 days and that of $u$ at a period of 151 days were observed and diagnosed to be barotropic planetary Rossby waves, based on dispersion relation (Imawaki 1985). Recently, Miyamoto et al. (2017) analyzed velocity data obtained by mooring observations at station $\mathrm{RB}\left(30^{\circ} 00^{\prime} \mathrm{N}, 147^{\circ} 08^{\prime} \mathrm{E}\right.$; Fig. 1b) during $1978-85$ and at RI $\left(30^{\circ} 02^{\prime} \mathrm{N}, 146^{\circ} 08^{\prime} \mathrm{E}\right)$ during $1980-83$, and found strong mesoscale variability of $v$ at periods of 45-75 days, which was considered to be TRWs under stratification rather than (a)

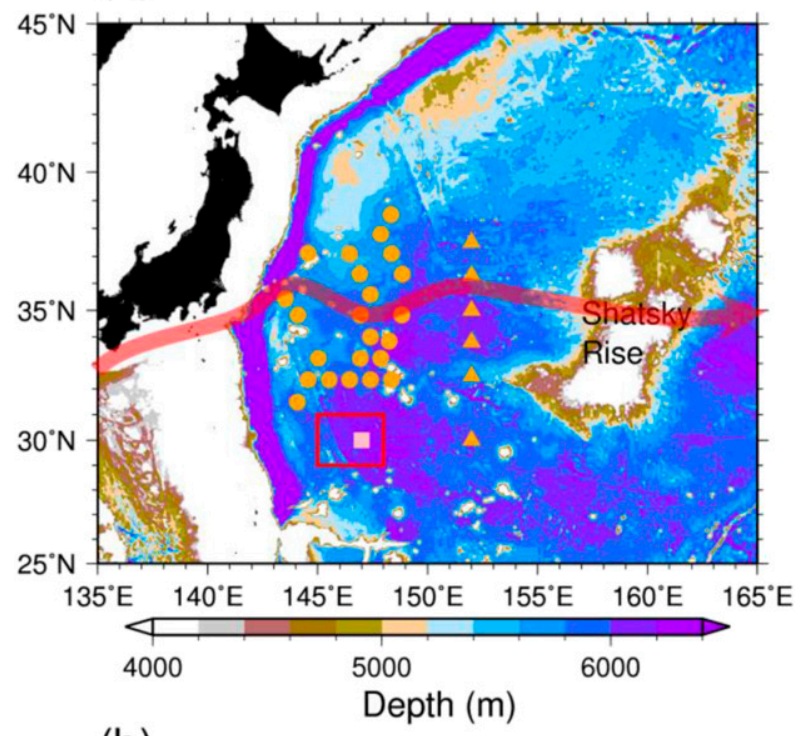

(b)

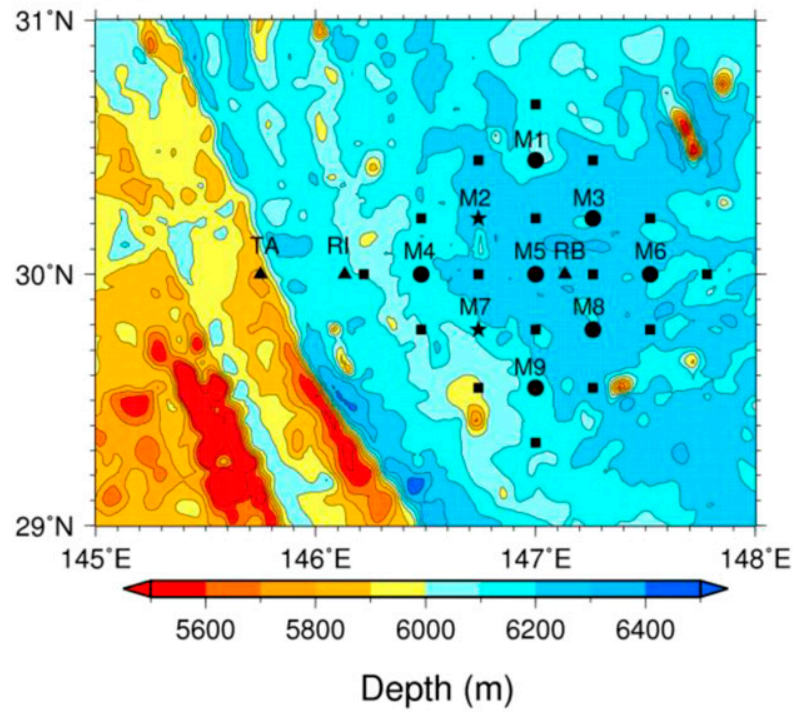

FIG. 1. (a) Locations of site $\mathrm{R}$ (pink square) and mooring stations observed by the KESS project (Donohue et al. 2010; orange dots) and by Schmitz et al. (1987; orange triangles). Red arrow indicates typical pathway of the Kuroshio and Kuroshio Extension. The region indicated by red square is enlarged in (b). (b) Locations of stations M1-M9 (dots for recovered moorings and stars for unrecovered ones), stations RB, RI, and TA (triangles), and 17 CTD stations including one at M5 (squares). In both (a) and (b), color with thin black contours denotes bottom topography based on ETOPO1 (Amante and Eakins 2009).

barotropic planetary Rossby waves. An additional analysis of OGCM outputs suggested that the TRWs at those periods observed at site $\mathrm{R}$ were generated in the Kuroshio Extension flowing eastward around $36^{\circ} \mathrm{N}$, and their energy propagated southward. 
TABLE 1. Location, deployment and recovery dates, and duration of mooring observations at M1-M9.

\begin{tabular}{|c|c|c|c|c|c|}
\hline \multirow[b]{2}{*}{ Station } & \multicolumn{2}{|c|}{ Location } & \multirow[b]{2}{*}{ Deployment date } & \multirow[b]{2}{*}{ Recovery date } & \multirow[b]{2}{*}{ Duration (days) } \\
\hline & Latitude & Longitude & & & \\
\hline M1 & $30^{\circ} 27.0^{\prime} \mathrm{N}$ & $146^{\circ} 59.9^{\prime} \mathrm{E}$ & 18 May 2014 & 25 Oct 2015 & 525 \\
\hline M2 & $30^{\circ} 13.5^{\prime} \mathrm{N}$ & $146^{\circ} 44.4^{\prime} \mathrm{E}$ & 19 May 2014 & - & - \\
\hline M3 & $30^{\circ} 13.5^{\prime} \mathrm{N}$ & $147^{\circ} 15.7^{\prime} \mathrm{E}$ & 18 May 2014 & 03 Jun 2016 & 747 \\
\hline M4 & $30^{\circ} 00.1^{\prime} \mathrm{N}$ & $146^{\circ} 29.1^{\prime} \mathrm{E}$ & 19 May 2014 & 27 Oct 2015 & 526 \\
\hline M5 & $30^{\circ} 00.0^{\prime} \mathrm{N}$ & $147^{\circ} 00.0^{\prime} \mathrm{E}$ & 17 May 2014 & 25 Oct 2015 & 526 \\
\hline M6 & $30^{\circ} 00.1^{\prime} \mathrm{N}$ & $147^{\circ} 31.4^{\prime} \mathrm{E}$ & 17 May 2014 & 25 Oct 2015 & 526 \\
\hline M7 & $29^{\circ} 46.5^{\prime} \mathrm{N}$ & $146^{\circ} 44.4^{\prime} \mathrm{E}$ & 15 May 2014 & - & - \\
\hline M8 & $29^{\circ} 46.5^{\prime} \mathrm{N}$ & $147^{\circ} 15.5^{\prime} \mathrm{E}$ & 17 May 2014 & 02 Jun 2016 & 747 \\
\hline M9 & $29^{\circ} 33.5^{\prime} \mathrm{N}$ & $146^{\circ} 59.5^{\prime} \mathrm{E}$ & 16 May 2014 & 26 Oct 2015 & 528 \\
\hline
\end{tabular}

To further clarify differences in characteristics, mechanism, and energy propagation of deep mesoscale variability among various periods, we conducted high-density, twodimensional mooring observations at site $\mathrm{R}$ in 2014-16. Because site $\mathrm{R}$ is located away from deep circulation currents (Kawabe and Fujio 2010) and $600 \mathrm{~km}$ south of the Kuroshio Extension, the mooring observations there were expected to detect deep mesoscale variability propagating over relatively flat bottom topography in the interior region. At site R, we deployed nine moorings (stations M1-M9) in a $3 \times 3$ diamond shape, whose zonal and meridional widths were both $100 \mathrm{~km}$ (Fig. 1b; Table 1). We attached two to four current meters to each mooring below a depth of $3000 \mathrm{~m}$. The horizontal and vertical resolutions of these moorings enable us to clarify horizontal and vertical structure of deep mesoscale variability. In this study, we analyze velocity data obtained by our mooring observations together with past mooring observations in the northwest Pacific basin and 10-yr long outputs of an eddy-resolving OGCM.

In the following section, we describe the data from our two-dimensional mooring observations during 2014-16, past mooring observations in the northwest Pacific basin, and the OGCM. In section 3, we investigate characteristics and mechanism of deep mesoscale variability by analyzing the velocity data obtained by our two-dimensional mooring observations and the past mooring observations around site R during 1978-85. We demonstrate that the mesoscale variability at periods of 58 and 174 days propagated as a single plane wave; the former corresponds to TRWs originated in the Kuroshio Extension region north of site $\mathrm{R}$, as revealed by Miyamoto et al. (2017). In section 4, we investigate characteristics and energy propagation of deep mesoscale variability at the period of 174 days in the northwest Pacific basin by analyzing the mooring

TABLE 2. Statistics estimated from daily velocities obtained by current meters at depths of 3000, 4000, 5000, and 6000 m at M1-M9.

\begin{tabular}{|c|c|c|c|c|c|c|c|}
\hline Station & Depth (m) & Current meter & $\bar{u}\left(\mathrm{~cm} \mathrm{~s}^{-1}\right)$ & $\bar{v}\left(\mathrm{~cm} \mathrm{~s}^{-1}\right)$ & $\sqrt{\overline{\overline{u^{\prime 2}}}}\left(\mathrm{~cm} \mathrm{~s}^{-1}\right)$ & $\sqrt{\overline{v^{\prime 2}}}\left(\mathrm{~cm} \mathrm{~s}^{-1}\right)$ & $\operatorname{EKE}\left(\mathrm{cm}^{2} \mathrm{~s}^{-2}\right)$ \\
\hline \multirow[t]{4}{*}{ M1 } & 3000 & SEAGUARD & -1.2 & 0.8 & 3.7 & 4.8 & 18.3 \\
\hline & 4000 & RCM-11 & -1.5 & 0.7 & 3.3 & 4.4 & 14.9 \\
\hline & 5000 & RCM-11 & -1.8 & 0.5 & 3.2 & 4.4 & 14.6 \\
\hline & 6000 & $\mathrm{ADCP}$ & -2.7 & 0.7 & 4.2 & 5.5 & 23.8 \\
\hline \multirow[t]{2}{*}{ M3 } & 4000 & Aquadopp & -1.1 & 1.3 & 3.6 & 3.4 & 12.2 \\
\hline & 6000 & RCM-11 & -1.2 & 1.5 & 3.9 & 3.7 & 14.3 \\
\hline \multirow[t]{4}{*}{ M4 } & 3000 & Aquadopp & -0.2 & -1.1 & 3.6 & 3.8 & 13.9 \\
\hline & 4000 & RCM-11 & -0.4 & -1.8 & 3.4 & 3.8 & 12.8 \\
\hline & 5000 & RCM-11 & -0.1 & -2.2 & 3.2 & 3.4 & 10.9 \\
\hline & 6000 & RCM-11 & -0.3 & -2.7 & 3.5 & 3.9 & 14.0 \\
\hline \multirow[t]{4}{*}{ M5 } & 3000 & SEAGUARD & -0.5 & 0.7 & 4.2 & 4.7 & 19.7 \\
\hline & 4000 & RCM-11 & -0.4 & 0.8 & 3.7 & 4.3 & 16.0 \\
\hline & 5000 & RCM-11 & -0.3 & 0.9 & 3.5 & 4.2 & 14.9 \\
\hline & 6000 & RCM-11 & -0.1 & 1.2 & 3.7 & 4.4 & 16.6 \\
\hline \multirow[t]{4}{*}{ M6 } & 3000 & SEAGUARD & -1.9 & 1.7 & 4.0 & 4.3 & 17.0 \\
\hline & 4000 & RCM-11 & -1.5 & 1.7 & 3.1 & 3.6 & 11.1 \\
\hline & 5000 & RCM-11 & -1.5 & 2.2 & 3.2 & 3.8 & 12.2 \\
\hline & 6000 & RCM-11 & -1.7 & 2.6 & 3.4 & 3.7 & 12.9 \\
\hline \multirow[t]{2}{*}{ M8 } & 4000 & Aquadopp & -1.5 & 0.5 & 3.2 & 3.9 & 12.8 \\
\hline & 6000 & RCM-11 & -2.1 & 0.6 & 3.1 & 3.7 & 11.8 \\
\hline \multirow[t]{3}{*}{ M9 } & 3000 & Aquadopp & -0.7 & -1.0 & 3.0 & 3.7 & 11.5 \\
\hline & 4000 & RCM-11 & -0.3 & -1.5 & 3.0 & 3.5 & 10.8 \\
\hline & 5000 & RCM-11 & 0.1 & -2.0 & 3.2 & 3.6 & 11.4 \\
\hline
\end{tabular}


TABLE 3. Location, deployment and recovery dates, and duration of mooring observations at TA.

\begin{tabular}{|c|c|c|c|c|c|}
\hline \multirow[b]{2}{*}{ Observation No. } & \multicolumn{2}{|c|}{ Location } & \multirow[b]{2}{*}{ Deployment date } & \multirow[b]{2}{*}{ Recovery date } & \multirow[b]{2}{*}{ Duration (days) } \\
\hline & Latitude & Longitude & & & \\
\hline 1 & $29^{\circ} 59.4^{\prime} \mathrm{N}$ & $145^{\circ} 45.1^{\prime} \mathrm{E}$ & 30 Sep 1978 & 16 Mar 1979 & 167 \\
\hline 2 & $29^{\circ} 59.3^{\prime} \mathrm{N}$ & $145^{\circ} 45.3^{\prime} \mathrm{E}$ & 20 Mar 1979 & 23 Jul 1979 & 125 \\
\hline 3 & $30^{\circ} 00.4^{\prime} \mathrm{N}$ & $145^{\circ} 46.7^{\prime} \mathrm{E}$ & 26 Jul 1979 & 31 Oct 1979 & 97 \\
\hline 4 & $30^{\circ} 02.9^{\prime} \mathrm{N}$ & $145^{\circ} 43.1^{\prime} \mathrm{E}$ & 31 Oct 1979 & 14 Jun 1980 & 227 \\
\hline 5 & $30^{\circ} 00.0^{\prime} \mathrm{N}$ & $145^{\circ} 45.4^{\prime} \mathrm{E}$ & 14 Jun 1980 & 16 Apr 1981 & 306 \\
\hline 6 & $29^{\circ} 58.5^{\prime} \mathrm{N}$ & $145^{\circ} 45.2^{\prime} \mathrm{E}$ & 16 Apr 1981 & 10 Mar 1982 & 328 \\
\hline 7 & $30^{\circ} 00.0^{\prime} \mathrm{N}$ & $145^{\circ} 46.5^{\prime} \mathrm{E}$ & 12 Mar 1982 & 19 Jul 1982 & 129 \\
\hline
\end{tabular}

observation data and outputs of OGCM, and clarify that observed deep mesoscale variability was TRWs originated at the eastern slope of the Shatsky Rise. In section 5, we summarize and discuss the results.

\section{Data and method}

Nine moorings (stations M1-M9) were deployed at site R in a $3 \times 3$ diamond shape during 16-18 May 2014 in the KS-14-7 cruise of R/V Shinsei-maru (Table 1; Fig. 1b). We attached four current meters at depths of 3000, 4000, 5000, and $6000 \mathrm{~m}$ to M1, M4, M5, M6, and M9 and two current meters at depths of 4000 and $6000 \mathrm{~m}$ to M2, M3, M7, and M8. Seventeen CTD observations were also conducted around the mooring stations during 17-23 May (Fig. 1b). All the moorings were planned to be recovered in the KS-15-14 cruise of R/V Shinsei-maru in October 2015. However, due to bad sea conditions, only five moorings (M1, M4, M5, M6, and M9) were recovered during 25-27 October. Out of the four remaining moorings, two (M3 and M8) were recovered 7 months later (2-3 June 2016) in the KH-16-3 cruise of R/V Hakuho-maru, but the other two (M2 and M7) were not able be recovered, possibly due to a battery shortage of the acoustic release transponders.

Through these two-dimensional mooring observations, velocity data were obtained in good quality (Table 2), except at a depth of $6000 \mathrm{~m}$ at M9, by using 15 Aanderaa RCM-11s, three Aanderaa SEAGUARDs, four Nortek Aquadopps, and one Teledyne RD Instrument Workhorse Sentinel 300-kHz acoustic Doppler current profiler (ADCP), which commonly measured velocities by using Doppler shift of backscattered acoustic signals. Because RCM-11 and SEAGUARD estimate current speed by using a constant sound speed of $1500 \mathrm{~m} \mathrm{~s}^{-1}$, we increased their current speeds by $0.4 \%$, $1.6 \%, 2.8 \%$, and $4.0 \%$ at $3000-, 4000-, 5000-$, and $6000-\mathrm{m}$ depths, respectively, based on sound speed estimated from
CTD observations around mooring stations (Fig. 1b). Furthermore, because each acoustic Doppler current meter has statistical speed bias (Hogg and Frye 2007; Watts et al. 2013), we further increased current speeds obtained by RCM-11 s by $5 \%$ and decreased those obtained by SEAGUARDs and Aquadopps by $5 \%$ and $7 \%$, respectively, based on intercomparison of velocities measured by various current meter models at a depth of $4000 \mathrm{~m}$ in the Drake Passage (Watts et al. 2013). As an intercomparison between the $300-\mathrm{kHz}$ ADCP and other current meter models in the deep ocean has not been reported, the velocities obtained by ADCP were not corrected. After filtering out inertial oscillations and diurnal and semidiurnal tides by using the Godin filter (Godin 1972), subsampled daily velocity data were analyzed.

We also analyzed past mooring observations at stations RB, RI, and TA $\left(30^{\circ} 00^{\prime} \mathrm{N}, 145^{\circ} 45^{\prime} \mathrm{E}\right.$; Fig. $\left.1 \mathrm{~b}\right)$ during $1978-85$ to resolve long-term variability observed by our two-dimensional mooring observations. At RB (RI), moorings were consecutively deployed from October 1978 to July 1985 (from August 1980 to May 1983), during which velocity data at a depth of $5000 \mathrm{~m}$ were obtained for 2463 (989) days by using mechanical current meter Aanderaa RCM-5 s, as detailed in Miyamoto et al. (2017) and Imawaki and Takano (2018). At TA, moorings were consecutively deployed from 30 September 1978 to 19 July 1982 with time gaps shorter than four days, and velocity data at depths of 4000, 5000, 5600, and $5800 \mathrm{~m}$ were obtained by Aanderaa RCM-5s (Tables 3 and 4 ). As the velocity data at a depth of $4000 \mathrm{~m}$ were lacking from 18 May to 13 June 1980 , those at a depth of $5000 \mathrm{~m}$ were used as a proxy.

To investigate mesoscale variability in the northwest Pacific basin, we also analyzed past mooring observations along $152^{\circ} \mathrm{E}$ between $30^{\circ}$ and $37.5^{\circ} \mathrm{N}$ from May 1980 to June 1982 (Schmitz et al. 1982, 1987; Fig. 1a). The velocity data

TABLE 4. Duration of velocity data and statistics estimated from daily velocities at depths of 4000, 5000, 5600, and 5800 m obtained by consecutive mooring observations at TA.

\begin{tabular}{cclcccccc}
\hline \hline Depth $(\mathrm{m})$ & Beginning date & Ending date & Duration (days) & $\bar{u}\left(\mathrm{~cm} \mathrm{~s}^{-1}\right)$ & $\bar{v}\left(\mathrm{~cm} \mathrm{~s}^{-1}\right)$ & $\sqrt{\overline{u^{\prime 2}}}\left(\mathrm{~cm} \mathrm{~s}^{-1}\right)$ & $\sqrt{\sqrt{v^{\prime 2}}}\left(\mathrm{~cm} \mathrm{~s}^{-1}\right)$ & ${\mathrm{EKE}\left(\mathrm{cm}^{2} \mathrm{~s}^{-2}\right)}$ \\
\hline 4000 & 20 Mar 1979 & 8 Jan 1981 & 660 & 1.5 & -2.8 & 2.2 & 3.5 & 8.4 \\
5000 & 20 Mar 1979 & 19 Jul 1982 & 1217 & 2.6 & -4.3 & 2.5 & 3.5 & 9.4 \\
5600 & 20 Mar 1979 & 15 Apr 1981 & 757 & 3 & -6 & 2.8 & 3.8 & 10.9 \\
5800 & 30 Sep 1978 & 29 Mar 1981 & 911 & 3 & -6.5 & 2.9 & 4.1 & 12.5 \\
\hline
\end{tabular}




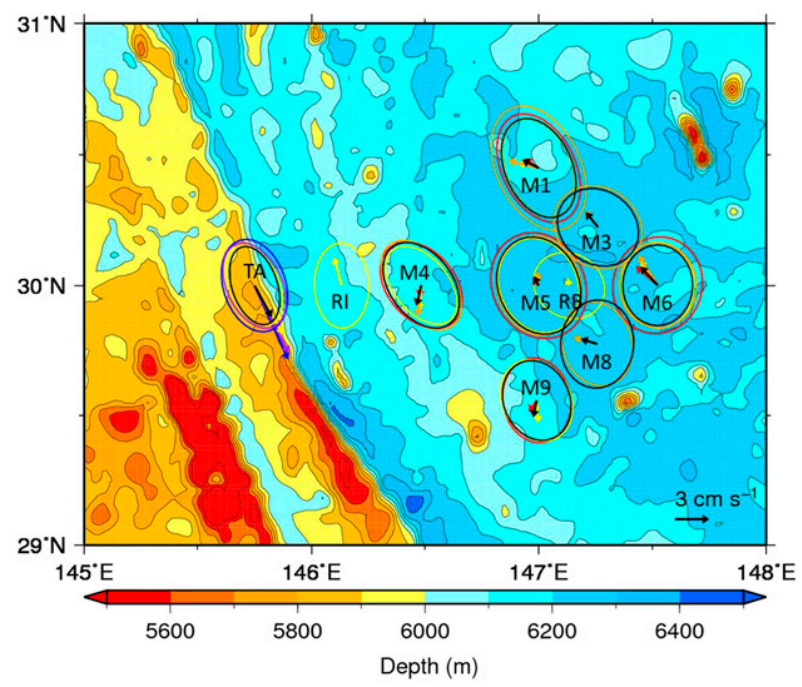

FIG. 2. Temporal mean velocities (arrows) and standard deviational ellipses based on the mooring observations at M1-M9, RB, RI, and TA. Red, black, yellow, and orange denote depths of 3000 , 4000, 5000, and $6000 \mathrm{~m}$, respectively. Purple and blue denote depths of 5600 and $5800 \mathrm{~m}$ at TA, respectively. Color with thin black contours indicates bottom topography based on ETOPO1.

obtained at a depth of $4000 \mathrm{~m}$ at six stations were downloaded online (https://www.nodc.noaa.gov/gocd/cmportal.html; Charles 2015). After filtering out inertial oscillations and diurnal and semidiurnal tides by using the Godin filter (Godin 1972), subsampled daily velocity data were analyzed.

We also used velocity data obtained in the Kuroshio Extension region by the Kuroshio Extension System Study (KESS; Donohue et al. 2010; Bishop et al. 2012; Greene et al. 2012; Tracey et al. 2012; Fig. 1a). Velocities were measured $50 \mathrm{~m}$ above the bottom by Aanderaa Doppler current sensors attached to inverted echo sounders from April 2004 to July 2006. The velocity data low-pass filtered by using a fourthorder Butterworth filter with a 72-h cutoff period were downloaded online (http:/www.po.gso.uri.edu/dynamics/ KESS/public_data/), and 23 stations providing data longer than 450 days were selected.

The numerical model used in this study is an eddy-resolving OGCM, based on the CCSR Ocean Component Model (COCO; Hasumi 2015). The horizontal resolution of the spherical coordinate region is $0.1^{\circ}$ (longitude) $\times 0.1^{\circ} \cos \theta$ (latitude), where $\theta$ is the latitude. There are 62 vertical levels with increasing layer thicknesses from $2 \mathrm{~m}$ at the surface to $660 \mathrm{~m}$ at the bottom depth of $7200 \mathrm{~m}$. The bottom topography is based on ETOPO1 (Amante and Eakins 2009) and represented by using a partial step formulation (Adcroft et al. 1997). The initial potential temperature and salinity are based on the Polar Science Center Hydrographic Climatology (Steele et al. 2001). The model is driven by the Coordinated Ocean-Ice Reference Experiments interannual forcing version 2 from 1950 to 2006 (Large and Yeager 2009). Further details of this model were described in Miyamoto et al. (a)
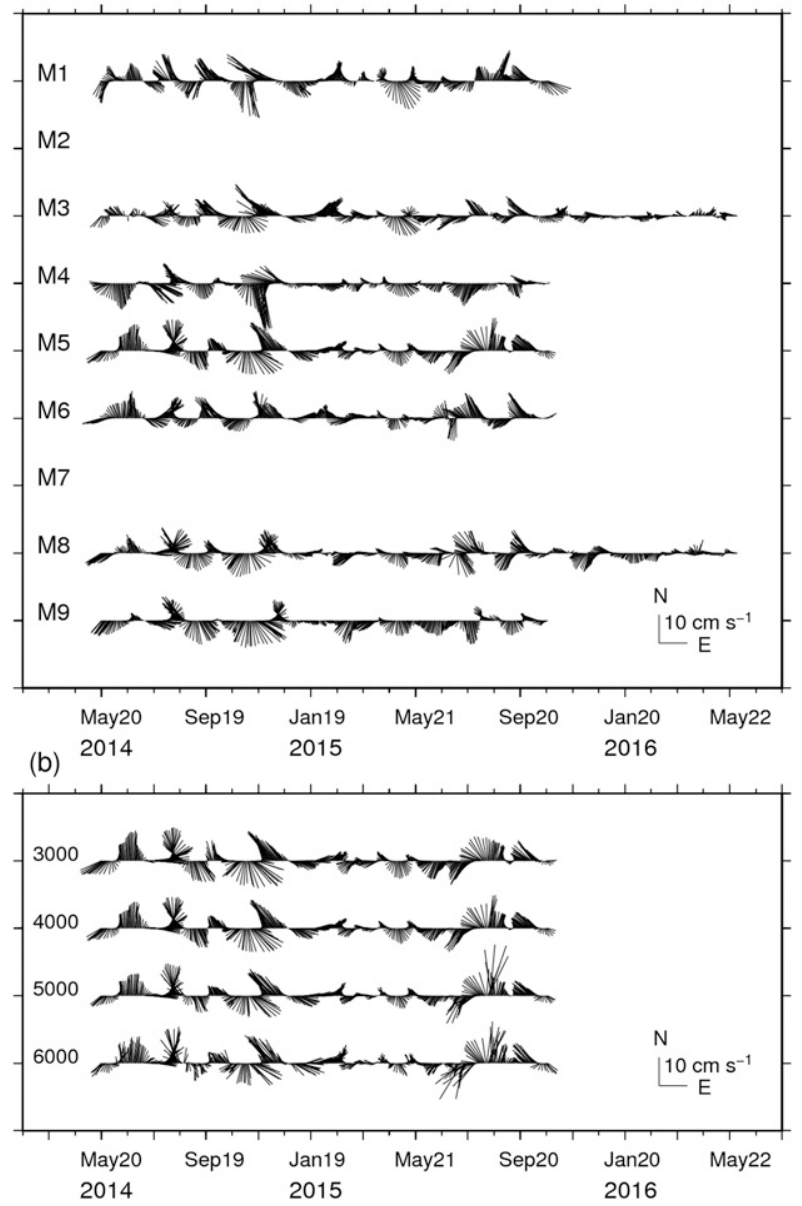

FIG. 3. Time series of daily velocities (a) at a depth of $4000 \mathrm{~m}$ at M1-M9 and (b) at depths of 3000, 4000, 5000, and $6000 \mathrm{~m}$ at M5, obtained by mooring observations during 2014-16.

(2017). In this study, we analyze 5-day mean $u$ and $v$ in 19972006, as in Miyamoto et al. (2017).

To investigate the characteristics and mechanism of deep mesoscale variability, we carried out spectral analysis for velocity data in the same way as Miyamoto et al. (2017). We first removed temporal mean velocities and tapered the whole time series by a Hanning window in the form of $[1-\cos (2 \pi t / T)] / 2$ ( $T$ is the total period; Thomson and Emery 2014). Then, we conducted Fourier transform of the time series and smoothed the calculated power spectral density (PSD) by using fivepoint (seven-point) triangular filters for our two-dimensional mooring observations (past mooring observations) because of shorter (longer) time series.

\section{Deep mesoscale variability observed around site $\mathbf{R}$}

The temporal mean of $u$ and $v(\bar{u}$ and $\bar{v}$; hereafter, overbar notation denotes the temporal mean of observation periods) were less than $3 \mathrm{~cm} \mathrm{~s}^{-1}$ in magnitude at all depths of $3000,4000,5000$, and $6000 \mathrm{~m}$ throughout stations M1-M9 (Fig. 2; Table 2). The mean current was northwestward at 

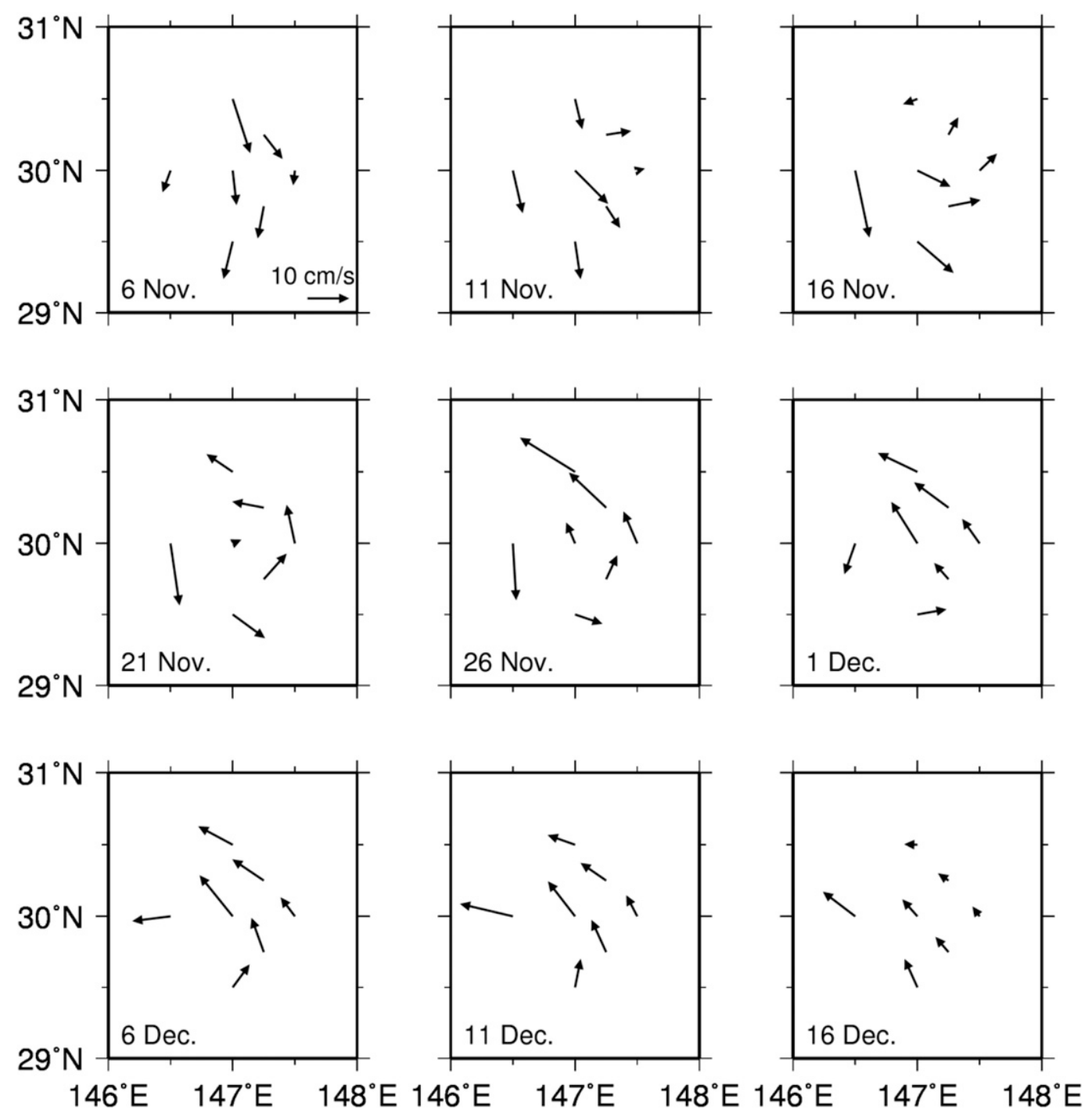

FIG. 4. Horizontal distribution of velocities at the depth of $4000 \mathrm{~m}$ obtained by mooring observations at M1-M9 from 6 Nov to 16 Dec 2014.

M1, M3, M5, M6, and M8 and southward at M4 and M9; it was not significantly different among the four depths at each station. The standard deviations $\sqrt{\overline{{u^{\prime 2}}^{2}}}$ and $\sqrt{\overline{{v^{\prime 2}}^{2}}}$ (prime notation denotes the deviation from the temporal mean) at M1-M9 were 3-5 $\mathrm{cm} \mathrm{s}^{-1}$, which were larger than the magnitude of $\bar{u}$ and $\bar{v}$ (Table 2), and the current variability was almost isotropic at all depths and stations (Fig. 2). The maximum eddy kinetic energy [EKE; $\left(\overline{u^{\prime 2}+v^{\prime 2}}\right) / 2$ ] of $23.8 \mathrm{~cm}^{2} \mathrm{~s}^{-2}$ was observed at a depth of $6000 \mathrm{~m}$ at M1 (Table 2). This high EKE was obtained only by the ADCP and may be overestimated because no correction was made, based on intercomparison with other current meter models. Except this high value, the EKEs were in a range of $11-20 \mathrm{~cm}^{2} \mathrm{~s}^{-2}$ and tended to be a little higher at depths of 3000 and $6000 \mathrm{~m}$ than 4000 and $5000 \mathrm{~m}$ at each station.
The time series of velocities at a depth of $4000 \mathrm{~m}$ at M1M9 indicated mesoscale variability with various time scales (Fig. 3a). Relative vorticity estimated from the velocities at the depth of $4000 \mathrm{~m}$ at M1, M4, M6, and M9 reached the maximum $\left(4.4 \times 10^{-6} \mathrm{~s}^{-1}\right)$ on 26 November 2014, when a cyclonic eddy-like feature, which was the only eddylike feature observed during the observation period, passed the mooring array from the northeast to southwest (Fig. 4). The corresponding vorticity Rossby number was low (0.06), suggesting that the observed mesoscale variability always satisfies the quasigeostrophic approximation. In addition, the mesoscale variability at each mooring station was vertically coherent among depths of 3000, 4000, 5000, and $6000 \mathrm{~m}$, as exemplified in Fig. 3b, and the correlation coefficient between $u(v)$ at the depth of $4000 \mathrm{~m}$ and that at 

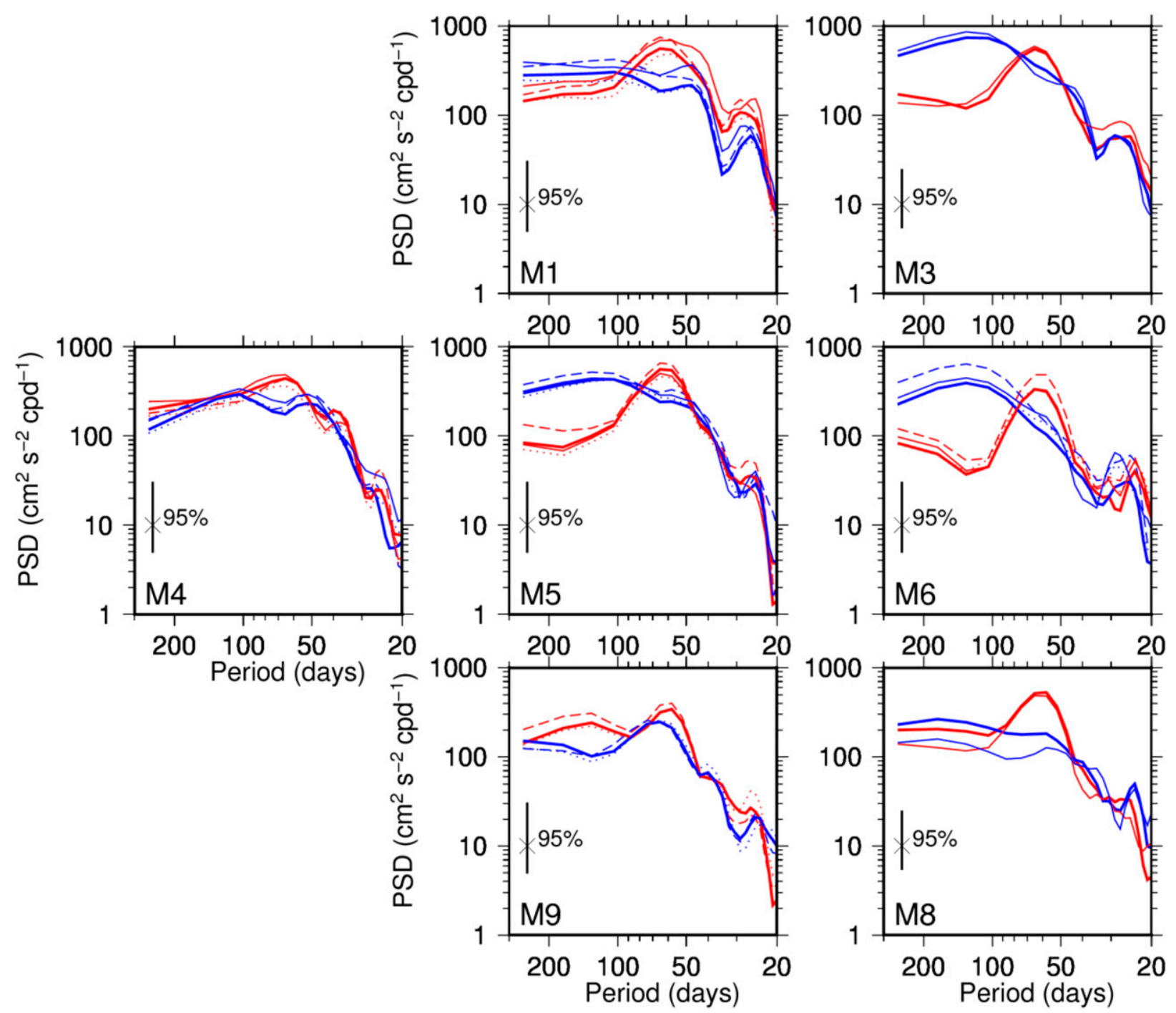

FIG. 5. PSDs of $u$ (blue) and $v$ (red) at depths of 3000 (dashed line), 4000 (thick line), 5000 (dotted line), and $6000 \mathrm{~m}$ (thin line) based on mooring observations at M1-M9 from 19 May 2014 to 25 Oct 2015. Bars indicate the $95 \%$ confidence interval.

depths of 3000,5000 , and $6000 \mathrm{~m}$ was higher than $0.91(0.93)$ throughout M1-M9.

To investigate time scales of the mesoscale variability, PSDs were estimated from $u$ and $v$ from 19 May 2014 to 25 October 2015, during which velocities were obtained throughout M1M9 (Table 1). The maxima of PSDs for $v$ were observed at periods of 58-65 days throughout M1-M9 and were comparable in magnitude among the depths of 3000-6000 $\mathrm{m}$ (Fig. 5). This resembles the strong mesoscale variability for $v$ at periods of 45-75 days at RB during 1978-85, which was considered to be TRWs under stratification (Miyamoto et al. 2017). On the other hand, the maxima of PSDs for $u$ were observed at periods of 103-261 days, ${ }^{1}$ at all the depths of 3000-6000 $\mathrm{m}$ at all stations

\footnotetext{
${ }^{1}$ The period of 261 days was the longest period estimated by our data and method.
}

except M9. This likely corresponds to the peak of PSD for $u$ at a period of 151 days in the mooring observations around site R from October 1978 to March 1979 (Imawaki 1985). Because the PSDs for each $u$ and $v$ were similar to each other among the depths of $3000-6000 \mathrm{~m}$ and coherence between $u(v)$ at the depth of $4000 \mathrm{~m}$ and that at depths of 3000,5000 , and $6000 \mathrm{~m}$, at each station of M1-M9, was higher than 95\% confidence level at periods longer than 20 days, and higher than 0.94 at periods longer than 50 days (not shown here), in the following part we analyze velocity data at the depth of $4000 \mathrm{~m}$, at which velocity data in good quality were obtained from all recovered moorings.

To clarify the orientation of deep mesoscale variability at each period, variance ellipses were estimated by using rotary spectrum of velocities (Thomson and Emery 2014) at M1-M9 (Fig. 6). The variance ellipses with the stability of mean orientation higher than the $95 \%$ confidence level were obtained 


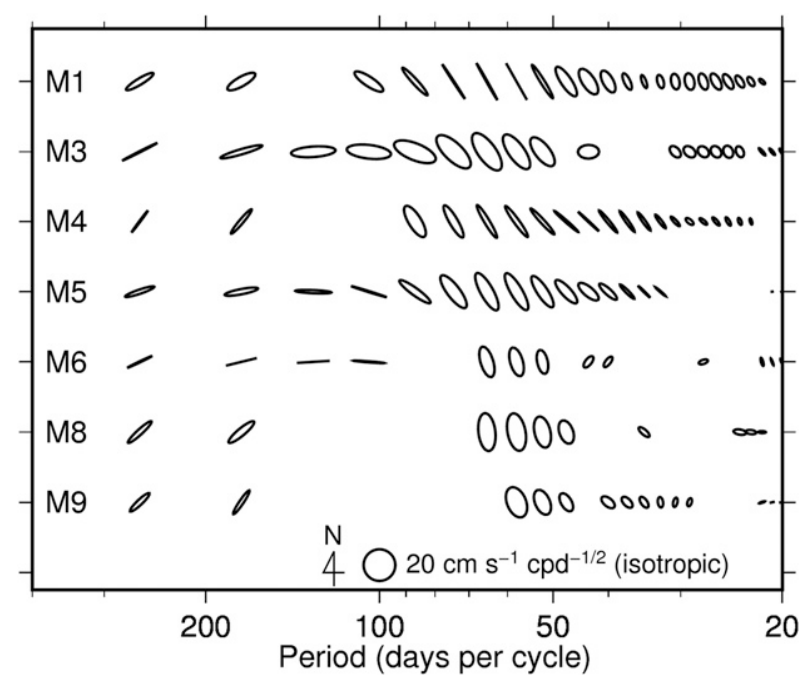

FIG. 6. Variance ellipses estimated by using rotary spectrum of current velocities (Thomson and Emery 2014) at the depth of $4000 \mathrm{~m}$ based on the mooring observations at M1-M9 from 19 May 2014 to 25 Oct 2015 . Note that only those ellipses with the stability of mean orientation higher than the $95 \%$ confidence level are plotted.

throughout M1-M9 only at periods of 52-58 and 174-261 days. Orientations of major axis of variance ellipses at the periods of 52-58 days at M1-M9, which corresponded to maximum PSDs of $v$ (Fig. 5), were $137^{\circ}-169^{\circ} \mathrm{T}$ (degrees true; clockwise angle from the north), while those at the periods of 174-261 days corresponding to maximum PSDs of $u$ except at M9, were $34^{\circ}-79^{\circ} \mathrm{T}$.

Because the time series of velocity data from our twodimensional mooring observations was not sufficiently long to resolve variability at the periods of 174-261 days, we recalculated PSDs for $u$ and $v$ at RB during 1978-85 by using narrower smoothing filters of PSD than those used in Miyamoto et al. (2017) (Fig. 7). The sum of PSDs has the largest maximum of $620 \mathrm{~cm}^{2} \mathrm{~s}^{-2} \mathrm{cpd}^{-1}$ with higher contribution from $u$ than $v$ at a period of 176 days, at which both of PSDs for $u$ and the stability of mean orientation for variance ellipses were high in our two-dimensional mooring observations (Figs. 5 and 6). We therefore focus on mesoscale variability at M1-M9 at the periods of 58 and 174 days in the following part.

To clarify the horizontal structure of the mesoscale variability by the two-dimensional mooring observations, magnitudesquared coherence (hereafter coherence) and phase lag were estimated at the depth of $4000 \mathrm{~m}$ between M5 and the other mooring stations. Coherence for $u$ and $v$ were statistically significant at $95 \%$ confidence level at almost all periods longer than 20 days and shorter than 100 days, respectively (Fig. 8). Contours of the phase lag for $u$ at the period of 174 days and $v$ at the period of 58 days clearly indicated phase propagations to the northwest and west-southwest, respectively (Fig. 9). The contours of the phase lag were nearly parallel to the major axis of variance ellipses, which indicated

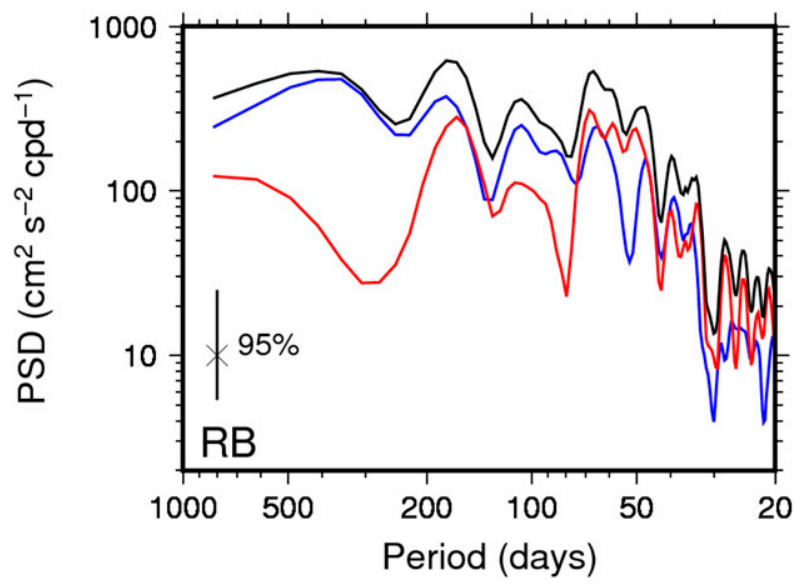

FIG. 7. PSDs for $u$ (blue), $v$ (red), and sum of them (black) at RB based on the mooring observations during 1978-85. The bar indicates the $95 \%$ confidence interval.

that the mesoscale variability at those two periods propagated as a single plane wave.

The averaged zonal and meridional wavenumbers $(k$ and $l)$ at the period of 58 days estimated from the phase lags for $v$ among moorings (Fig. 9b) were $-2.0 \times 10^{-5}$ and $-0.6 \times$ $10^{-5} \mathrm{~m}^{-1}$, which corresponded to wave propagation direction of west-southwest and wavelength of $310 \mathrm{~km}$. The zonal wavenumber was similar to that $\left(-2.6 \times 10^{-5} \mathrm{~m}^{-1}\right)$ estimated by Miyamoto et al. (2017) based on the phase lag for $v$ between RB and RI at a period of 47 days. Thus, the mesoscale variability at the period of 58 days was considered to be TRWs originated in the Kuroshio Extension region north of site $\mathrm{R}$, as demonstrated by Miyamoto et al. (2017).

The averaged $k$ and $l$ at the period of 174 days estimated from the phase lags for $u$ (Fig. 9a) were $-1.7 \times 10^{-5}$ and $1.4 \times 10^{-5} \mathrm{~m}^{-1}$, corresponding to wave propagation direction of northwest and the wavelength of $290 \mathrm{~km}$. As these wavenumbers did not satisfy the dispersion relation of planetary barotropic nor baroclinic Rossby waves (dashed and dotted circles in Fig. 10), we consider influence of stratification and slope of bottom topography on Rossby waves (Rhines 1970). The dispersion relation of TRW under stratification is given by

$$
\omega=\frac{-\beta k}{k^{2}+l^{2}-\lambda},
$$

where $\omega(>0)$ is the angular frequency, $\beta$ is the meridional gradient of the Coriolis parameter, and $\lambda$ is the eigenvalue of vertical mode. The eigenvalue problem is

$$
\begin{aligned}
\frac{d}{d z}\left(\frac{f_{0}^{2}}{N^{2}} \frac{d \phi}{d z}\right) & =\lambda \phi, \\
\frac{d \phi}{d z} & =0, \quad \text { at } z=0, \\
\frac{d \phi}{d z} & =\frac{N^{2}}{f_{0} \omega}\left(H_{y} k-H_{x} l\right) \phi, \text { at } z=-H,
\end{aligned}
$$


(a)

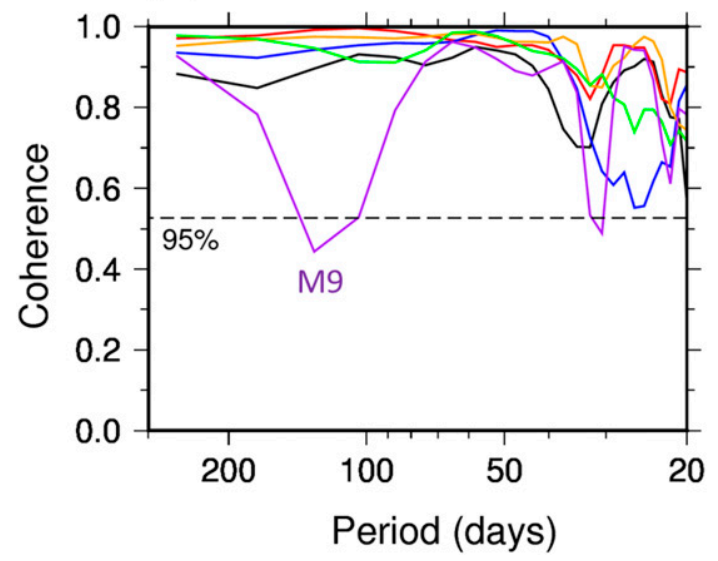

(b)

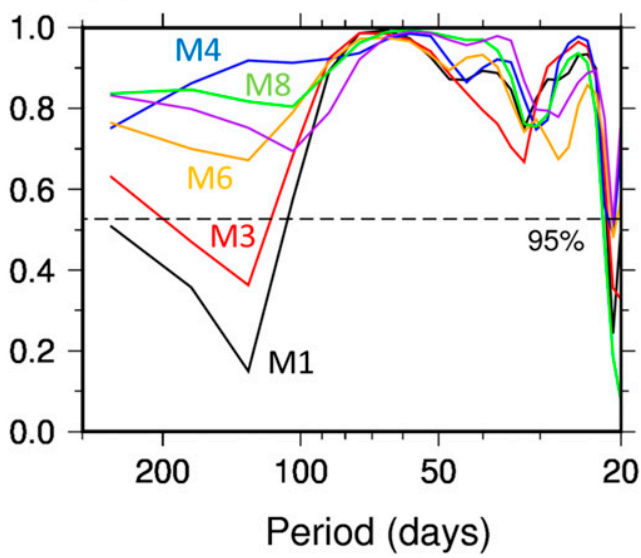

FIG. 8. Coherence for (a) $u$ and (b) $v$ at the depth of $4000 \mathrm{~m}$ between M5 and M1 (black), M3 (red), M4 (blue), M6 (orange), M8 (green), and M9 (purple) from 19 May 2014 to 25 Oct 2015. The dashed lines indicate the 95\% confidence level.

where $z$ is the vertical coordinate (positive upward), $f_{0}$ is the Coriolis parameter, $N(z)$ is the Brunt-Väisälä frequency, $\phi(z)$ is streamfunction as the eigenfunction, $H$ is water depth, and $H_{x}$ and $H_{y}$ are zonal and meridional gradient of $H$, respectively. Note that $\lambda$ of the lowest mode is positive (negative) when $\phi(z)$ of that mode is bottom (surface) intensified. At $30^{\circ} \mathrm{N}, 147^{\circ} \mathrm{E}, f_{0}$ is $7.3 \times 10^{-5} \mathrm{~s}^{-1}$, and $H, H_{x}$, and $H_{y}$ were estimated to be $6180 \mathrm{~m}, 6.3 \times 10^{-4}$, and $5.2 \times 10^{-4}$, respectively, by fitting a plane to the bottom topography (ETOPO1; Amante and Eakins 2009) over a $2^{\circ} \times 2^{\circ}$ regional box, with Hanning weighting, which has a horizontal scale similar to the wavelength. The Brunt-Väisälä frequency was estimated from
CTD observations around the mooring stations (Fig. 1b). The wavenumbers estimated from phase lag (Fig. 9a) satisfied the dispersion relation of TRWs under stratification (solid circle in Fig. 10; Rhines 1970). Because the bottom topography is relatively flat around site $\mathrm{R}$ and the stratification in the deep ocean is weak, $\phi(z)$ estimated from Eqs. (2)-(4) was almost vertically uniform at depths of $3000-6000 \mathrm{~m}$, which was consistent with the vertically uniform distribution of PSDs at M1M9 (Fig. 5).

To examine the characteristics of bottom intensification of TRWs on sloping bottom topography (e.g., Rhines 1970; Thompson and Luyten 1976; Oey and Lee 2002), we further (a)

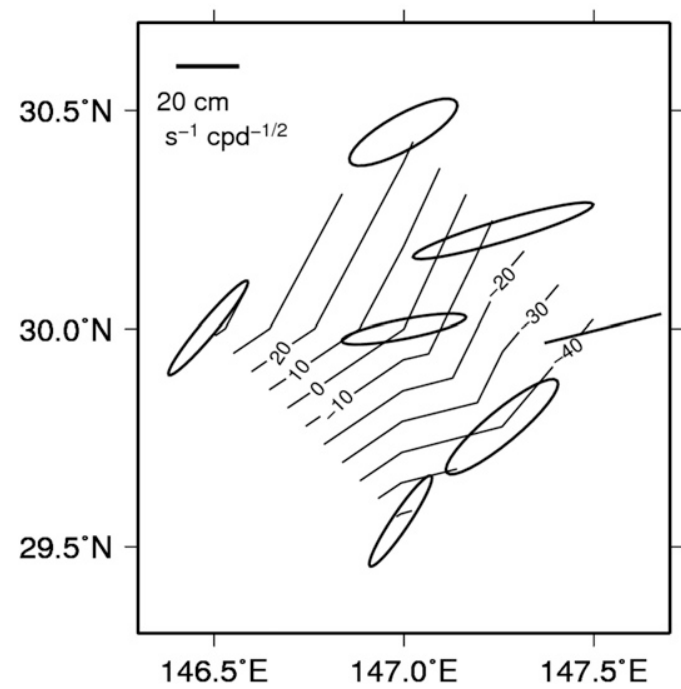

(b)

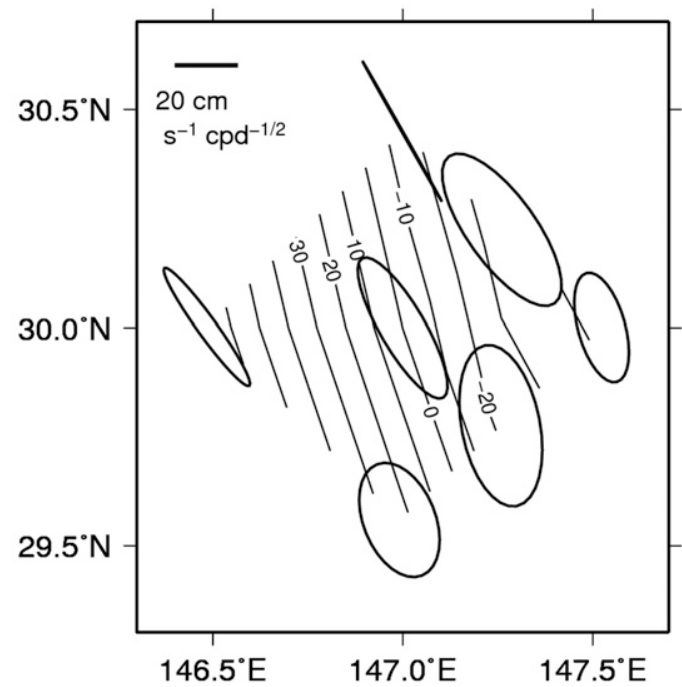

FIG. 9. Phase lags $\left(^{\circ}\right)$ (contours) between M5 and the other stations of M1-M9 at the depth of $4000 \mathrm{~m}$ for (a) $u$ at the period of 174 days and (b) $v$ at the period of 58 days. Ellipses indicate variance ellipses at periods of (a) 174 and (b) 58 days. 


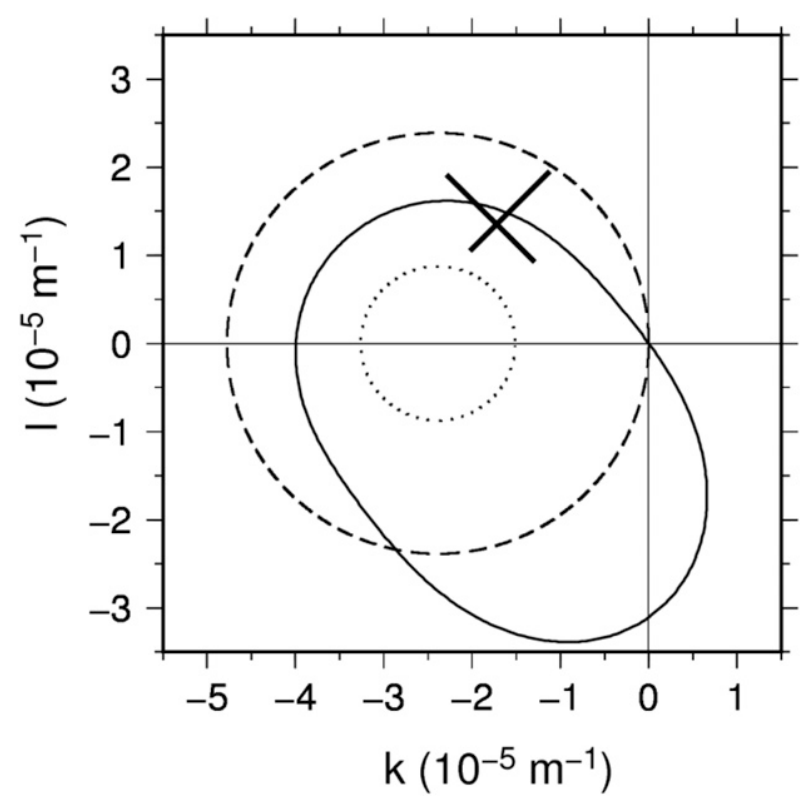

FIG. 10. Zonal and meridional wavenumbers (cross) estimated from the phase lag for $u$ at a period of 174 days at the depth of $4000 \mathrm{~m}$ at M1-M9 (Fig. 9a). The center of the cross denotes averaged wavenumbers, and lengths of the cross indicate the minimum and maximum of estimated wavenumbers. Dashed, solid, and dotted circles denote the dispersion relations of barotropic planetary Rossby wave, TRW, and baroclinic planetary Rossby wave, respectively, at the period of 174 days.

analyze velocity data during 1978-82 at depths of 4000, 5000, 5600 , and $5800 \mathrm{~m}$ at TA (Fig. 11, Table 4), which is located on bottom topography sloping up to west-southwest $(|\nabla H| \sim 0.01$; Fig. 1b). The temporal mean speed was intensified bottomward from $3.2 \mathrm{~cm} \mathrm{~s}^{-1}$ at a depth of $4000 \mathrm{~m}$ to $7.2 \mathrm{~cm} \mathrm{~s}^{-1}$ at a depth of $5800 \mathrm{~m}$ (50 $\mathrm{m}$ above the bottom) (Table 4; Fig. 2). The mean direction was south-southeast, along isobaths at all depths, and agreed with the direction of major axes of the standard deviational ellipses. The time series of velocities also indicated bottom intensification of mesoscale variability (Fig. 11), with EKE increasing from $8.4 \mathrm{~cm}^{2} \mathrm{~s}^{-2}$ at the depth of $4000 \mathrm{~m}$ to $12.5 \mathrm{~cm}^{2} \mathrm{~s}^{-2}$ at the depth of $5800 \mathrm{~m}$ (Table 4). The PSDs of $u$ and $v$ obtained at TA during 1979-81 also indicated bottom intensification from the depths of $4000-5800 \mathrm{~m}$ at periods of 94-219 days (Fig. 12), which was consistent with the characteristic of the TRWs on the bottom slope (Rhines 1970).

\section{Deep mesoscale variability at 174-day period}

To investigate relationship between the orientation of prominent mesoscale variability at periods of around 174 days and bottom topography, variance ellipses at periods of 150-200 days were estimated from velocity data at depths of more than $4000 \mathrm{~m}$ obtained by the past and our mooring observations in the northwest Pacific basin (Fig. 13). The major axes of variance ellipses at periods of 150-200 days with the stability of mean orientation higher than the $95 \%$ confidence level tended to be parallel to smoothed $f / H$ contours, not only around site $\mathrm{R}$ but also in the Kuroshio Extension region and along $152^{\circ} \mathrm{E}$, and $57 \%$ of cases differed by less than $30^{\circ}$ from parallel to the smoothed $f / H$ contours.

This relationship between the orientation of variance ellipses and $f / H$ contours was verified by using OGCM outputs. In the OGCM, EKE distribution estimated from velocities at the depth of $4000 \mathrm{~m}$ in the northwest Pacific basin indicated the maximum of higher than $32 \mathrm{~cm}^{2} \mathrm{~s}^{-2}$ around $36^{\circ} \mathrm{N}, 147^{\circ} \mathrm{E}$, where the Kuroshio Extension flows eastward in the surface layer (Fig. 14). Such an EKE distribution was similar to that estimated from mooring observations along $152^{\circ} \mathrm{E}$ (Schmitz 1988). Furthermore, standard deviational ellipses were nearly circular except around large seamounts (Fig. 15), which was also consistent with those estimated from the mooring observations around site $\mathrm{R}$ (Fig. 2) and in the Kuroshio Extension region (Donohue et al. 2010). Thus, the OGCM is considered to adequately reproduce distribution of deep mesoscale variability in the northwest Pacific basin.

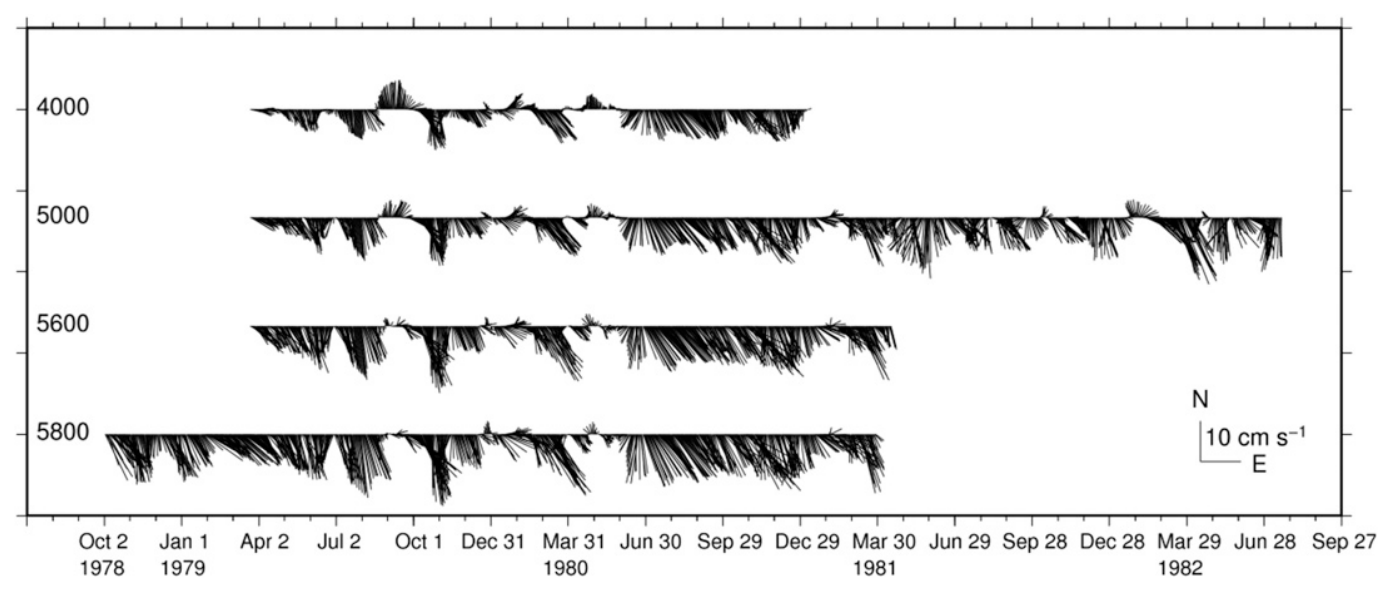

FIG. 11. Time series of daily velocities at depths of $4000,5000,5600$, and $5800 \mathrm{~m}$ obtained by mooring observations at TA during 1978-1982. 
(a)

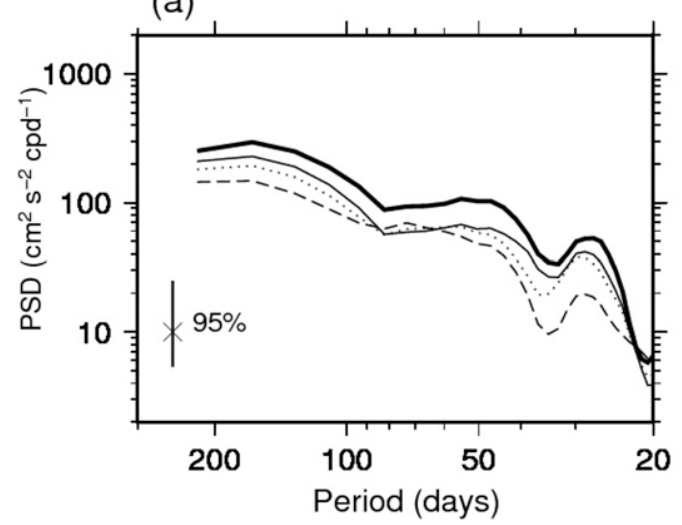

(b)

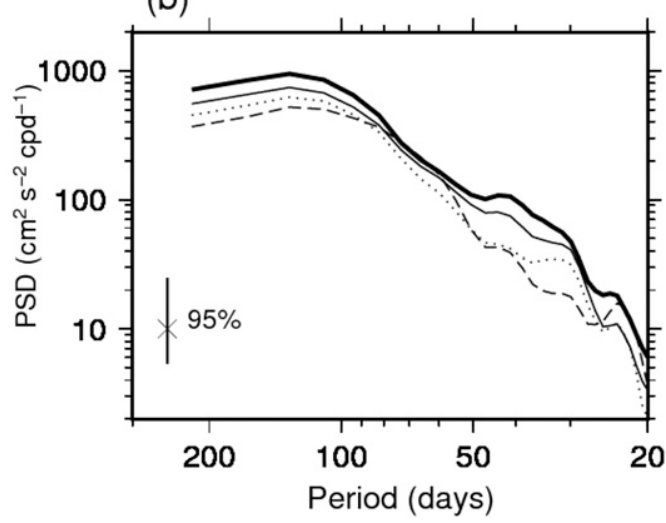

FIG. 12. The PSDs for (a) $u$ and (b) $v$ at depths of 4000 (dashed line), 5000 (dotted line), 5600 (thin line), and $5800 \mathrm{~m}$ (thick line) based on mooring observations at TA from 20 Mar 1979 to 8 Jan 1981. Bars indicate the $95 \%$ confidence interval.

The major axes of variance ellipses at the period of 174 days with the stability of mean orientation higher than the $99 \%$ confidence level tended to be parallel to smoothed $f / H$ contours, and the probability of the difference of angles within $\pm 30^{\circ}$ was $66 \%$ (Fig. 16b), which was similar to that $(57 \%$ ) estimated by the mooring observations in the northwest Pacific basin (Fig. 13). This tendency was also found at longer periods, for example, 365 days, at which the probability within $\pm 30^{\circ}$ was $69 \%$ (Fig. 16a). In contrast, at shorter periods, such as 54 and 27 days, the orientation of major axes of variance ellipses tended to be independent of $f / H$ contours (Figs. 16c,d). This tendency was consistent with theoretical studies of low-frequency wave motions under the shallow water assumption (Rhines 1969; Gill and Parker 1970; appendix A).

When the direction of variability (wavenumber vectors) of TRWs tends to be parallel (perpendicular) to $f / H$ contours, the group velocity of TRWs is expected to be along $f / H$ contours under the long-wave approximation. To investigate the energy propagation of TRWs, we conducted backward ray tracing of TRWs (Pickart 1995) at the period of 174 days from site $\mathrm{R}$ for
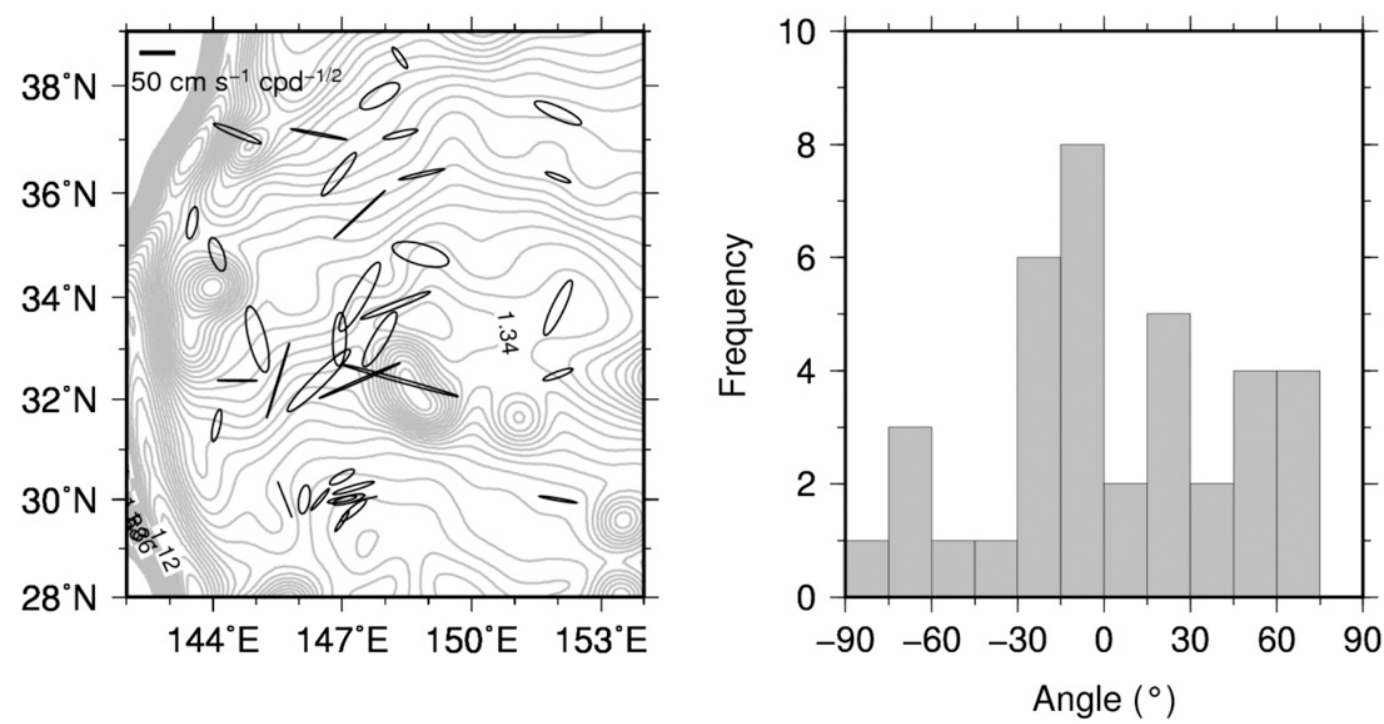

FIG. 13. (left) Variance ellipses at periods of 150-200 days with the stability of mean orientation higher than the $95 \%$ confidence level. They were estimated from velocity data at depths of more than $4000 \mathrm{~m}$ obtained by mooring observations around site R during 1978-85 and 2014-16, along $152^{\circ} \mathrm{E}$ during 1980-82 (Schmitz et al. 1987), and in the Kuroshio Extension region during 2004-06 (Donohue et al. 2010). Gray contours denote $f / H\left(10^{-8} \mathrm{~m}^{-1} \mathrm{~s}^{-1}\right)$, where $H$ is smoothed bottom topography estimated by fitting a plane to the bottom topography based on ETOPO1 over a $2^{\circ} \times 2^{\circ}$ regional box. (right) Histograms of angles between $f / H$ contours and the major axes of variance ellipses. 


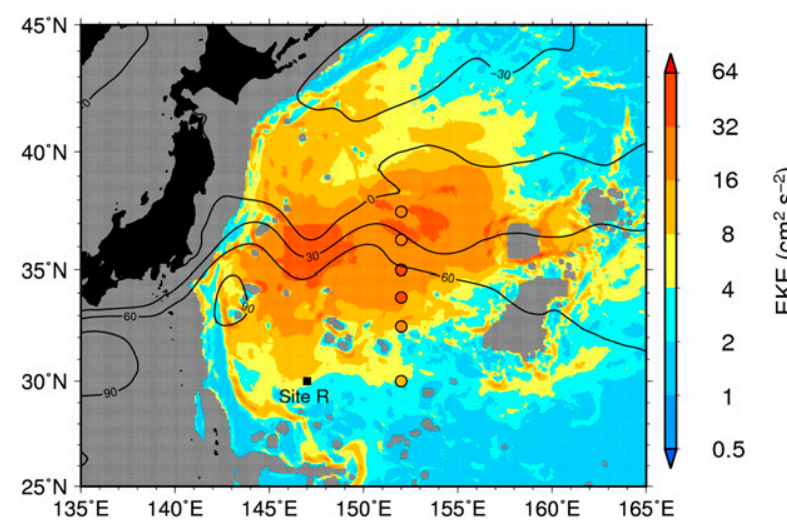

FIG. 14. Distribution of EKE at the depth of $4000 \mathrm{~m}$ based on the OGCM outputs (color) and mooring observations (Schmitz 1988; color shading inside circle). Contours indicate the 10 -yr mean sea surface height $(\mathrm{cm})$. Square denotes the location of site R. Gray shading represents regions shallower than $4000 \mathrm{~m}$.

350 days (Fig. 17). The group velocity $\mathbf{c}_{g}$ and the time derivative of wavenumber vector $\mathbf{k}$ were integrated in time by using the following equations:

$$
\begin{aligned}
& \mathbf{c}_{g}=\frac{\partial \omega}{\partial \mathbf{k}} \\
& \frac{d \mathbf{k}}{d t}=-\frac{\partial \omega}{\partial H} \nabla H-\frac{\partial \omega}{\partial H_{x}} \nabla H_{x}-\frac{\partial \omega}{\partial H_{y}} \nabla H_{y},
\end{aligned}
$$

where $\mathbf{k}=(k, l)$ is the wavenumber vector and $d / d t=\partial / \partial t+$ $\mathbf{c}_{g} \cdot \nabla$ (Pickart 1995). The initial $k$ and $l$ for ray tracing were set at $-1.7 \times 10^{-5}$ and $1.5 \times 10^{-5} \mathrm{~m}^{-1}$, which satisfy the dispersion relation [Eq. (1)] at site $\mathrm{R}$. The choice of different values for initial $k$ and $l$ did not alter the result significantly (appendix B). In the calculation, we estimated $H, H_{x}$, and $H_{y}$ by fitting of a plane as described above after shaving off isolated seamounts shallower than $5600 \mathrm{~m}$. Note that although the ray tracing theory uses the Wentzel-Kramers-Brillouin assumption in which the bottom topography varies on a scale much larger than the wavelength, empirically the ray tracing works well beyond this assumption (Pickart 1995).

The ray was traced back northeastward from site $\mathrm{R}\left(30^{\circ} \mathrm{N}\right.$, $147^{\circ} \mathrm{E}$ ) to $31^{\circ} \mathrm{N}, 148.5^{\circ} \mathrm{E}$, and then eastward almost along $\mathrm{f} / \mathrm{H}$ contours (Fig. 17), which was consistent with the orientation of major axis of variance ellipses (Fig. 16b). The ray turned northward at $31^{\circ} \mathrm{N}, 160^{\circ} \mathrm{E}$ and finally reached the eastern slope of the Shatsky Rise at $35^{\circ} \mathrm{N}, 161^{\circ} \mathrm{E}$. This contrasts with a ray at the period of 58 days, which traced back northward from north of site $\mathrm{R}$ to $35^{\circ} \mathrm{N}, 148^{\circ} \mathrm{E}$ in the Kuroshio Extension region (Miyamoto et al. 2017). Such contrast is consistent with an observational study around Gulf Stream, which suggested that the origin of TRWs shifts eastward with increasing their period (Bower and Hogg 1992).

\section{Summary and discussion}

To clarify characteristics and mechanism of mesoscale variability in the deep ocean, we conducted two-dimensional

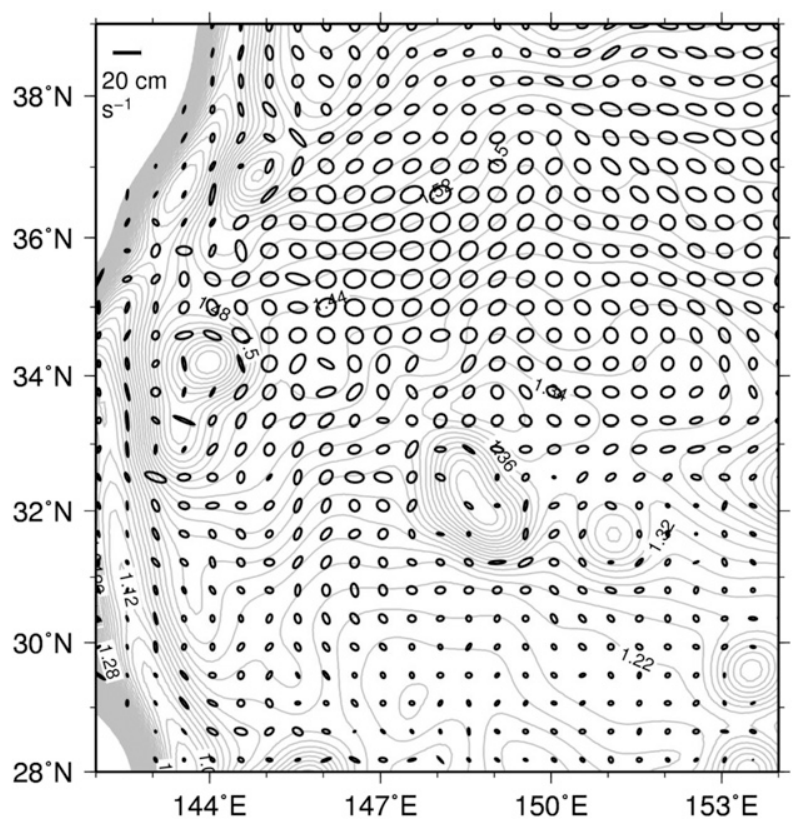

FIG. 15. Standard deviational ellipses at the depth of $4000 \mathrm{~m}$ based on the OGCM outputs, plotted every $0.5^{\circ}$ in longitude and latitude. Gray contours represent $f / H\left(10^{-8} \mathrm{~m}^{-1} \mathrm{~s}^{-1}\right)$ based on smoothed bottom topography.

mooring observations (stations M1-M9) around site R during 2014-16, and analyzed velocity data obtained at depths of $3000,4000,5000$, and $6000 \mathrm{~m}$ together with previous mooring observation data obtained around site $\mathrm{R}$ (stations RB, RI, and TA) during 1978-85. We also analyzed past mooring observation data obtained in the Kuroshio Extension region and along $152^{\circ} \mathrm{E}$, and outputs of an eddy-resolving OGCM to investigate characteristics and energy propagation of the deep mesoscale variability in the northwest Pacific basin.

In the two-dimensional mooring observations, mesoscale variability was almost vertically uniform at all periods, and therefore velocity data at the depth of $4000 \mathrm{~m}$ were mainly analyzed. The variability of $u$ and $v$ was prominent at periods of 174 and 58 days, respectively, at which the stability of mean orientation of variance ellipses was higher than the $95 \%$ confidence level. The contours of the phase lag for $u$ at the period of 174 days and $v$ at the period of 58 days among mooring stations indicated phase propagation to the northwest and west-southwest, respectively, and were nearly parallel to the major axis of variance ellipses, indicating that the mesoscale variability at those two periods propagated as a single plane wave. At the period of 58 days, $k$ and $l$ estimated from the phase lag for $v$ among the stations were $-2.0 \times 10^{-5}$ and $-0.6 \times 10^{-5} \mathrm{~m}^{-1}$, respectively. Because this $k$ was similar to that $\left(-2.6 \times 10^{-5} \mathrm{~m}^{-1}\right)$ estimated from the phase lag between RB and RI at a similar period of 47 days (Miyamoto et al. 2017), the mesoscale variability was considered to be TRWs under stratification originated in the Kuroshio Extension region north of site $\mathrm{R}$, as revealed by Miyamoto et al. (2017). The $k$ and $l$ at the period of 174 days estimated from the phase lag for $u$ were $-1.7 \times 10^{-5}$ and $-1.4 \times 10^{-5} \mathrm{~m}^{-1}$, respectively, which also 

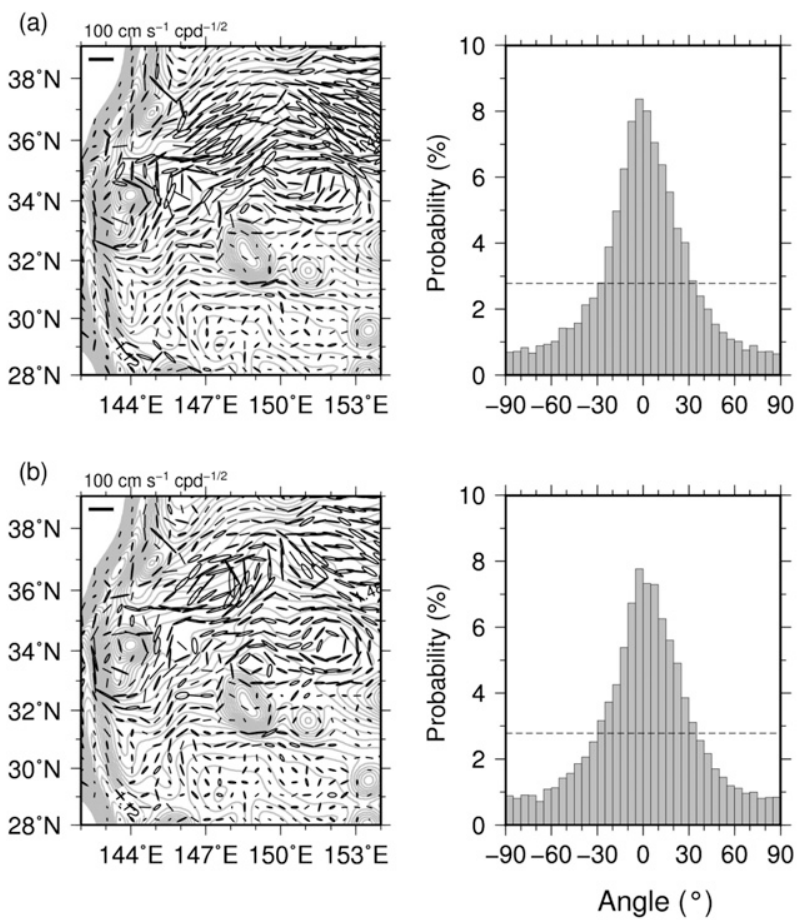
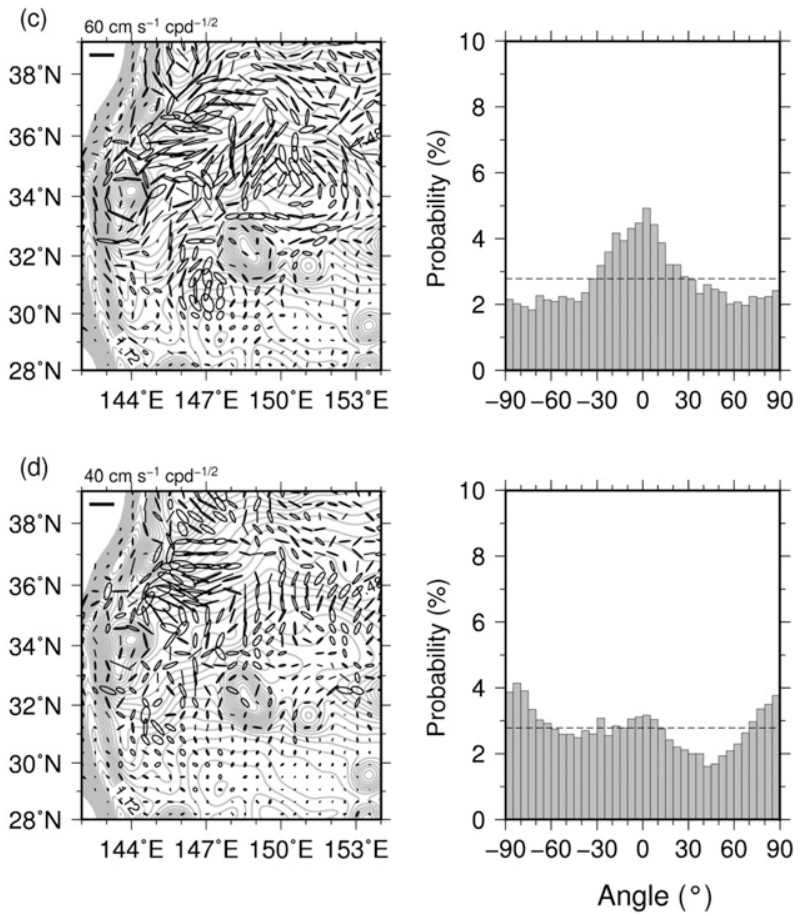

FIG. 16. (left) Variance ellipses with the stability of mean orientation higher than the $99 \%$ confidence level at periods of (a) 365 , (b) 174 , (c) 54 , and (d) 27 days at the depth of $4000 \mathrm{~m}$, based on the outputs of OGCM. Gray contours denote $f / H\left(10^{-8} \mathrm{~m}^{-1} \mathrm{~s}^{-1}\right)$ based on smoothed bottom topography. Note that the scales of variance ellipses in (c) and (d) are different from those in (a) and (b). (right) Histograms of probability of angles between $f / H$ contours and the major axes of variance ellipses shown in corresponding left panels. Dashed line indicates the uniform probability $(2.8 \%)$.

satisfied the dispersion relation of the TRWs under stratification. The mesoscale variability observed at M1-M9 (TA) was vertically uniform (bottom intensified), which was consistent with the vertical structure of TRWs at relatively flat (sloping) bottom topography.

To investigate the orientation of prominent mesoscale variability, variance ellipses were estimated from velocity data obtained by the past mooring observations in the northwest Pacific basin and the outputs of OGCM. The orientation of major axis of variance ellipses at periods of around 150-200 days tended to be parallel to $f / H$ contours in both the observation and the OGCM. This tendency was found at longer periods such as 365 days and not found at shorter periods such as 54 and 27 days on the basis of the OGCM outputs. A backward ray of TRWs at the period of 174 days from site $\mathrm{R}$ also tended to be parallel to $f / H$ contours, which was consistent with the orientation of major axis of variance ellipses. The ray was traced back to the eastern slope of the Shatsky Rise, where was considered to be origin of TRWs because some theoretical studies indicated that TRWs were generated when jets such as the Kuroshio Extension encountered sloping bottom topography (Malanotte-Rizzoli et al. 1995).

As mentioned in section 1, it was recently suggested from observations that flow in the interior regions transports deep water from the subpolar region to the subtropical region of the North Atlantic (Bower et al. 2009, 2011). OGCM analyses and idealized numerical studies also suggested that deep recirculation gyres of a jet, such as the Gulf Stream and the
Kuroshio Extension, which were driven by mesoscale variability (especially barotropic planetary Rossby waves) over flat bottom topography (Holland and Rhines 1980; Haidvogel and Rhines 1983; Waterman and Jayne 2012), transport deep water in the interior regions (Gary et al. 2011; Lozier et al. 2013). Therefore, deep recirculation gyres driven by TRWs under stratification generated in the Kuroshio Extension region may also play important role in transporting deep water over relatively flat bottom topography as well as DWBCs in the northwest

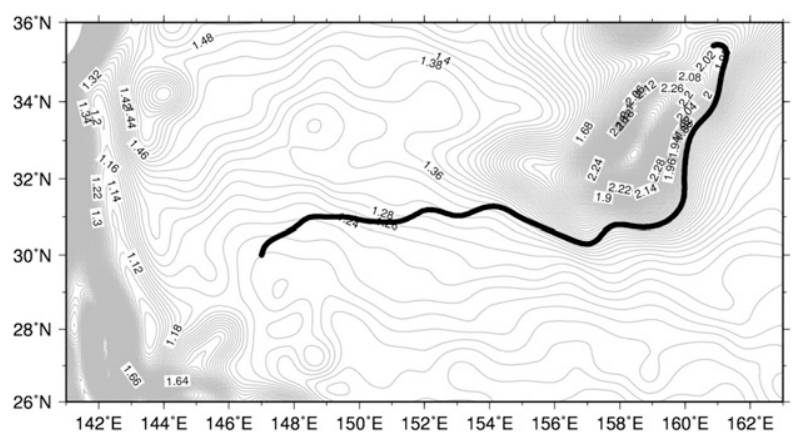

FIG. 17. Backward trajectory of a ray of TRWs at the period of 174 days from $30^{\circ} \mathrm{N}, 147^{\circ} \mathrm{E}$ for 350 days (thick black curve). Gray contours denote $f / H\left(10^{-8} \mathrm{~m}^{-1} \mathrm{~s}^{-1}\right)$ based on smoothed bottom topography. 


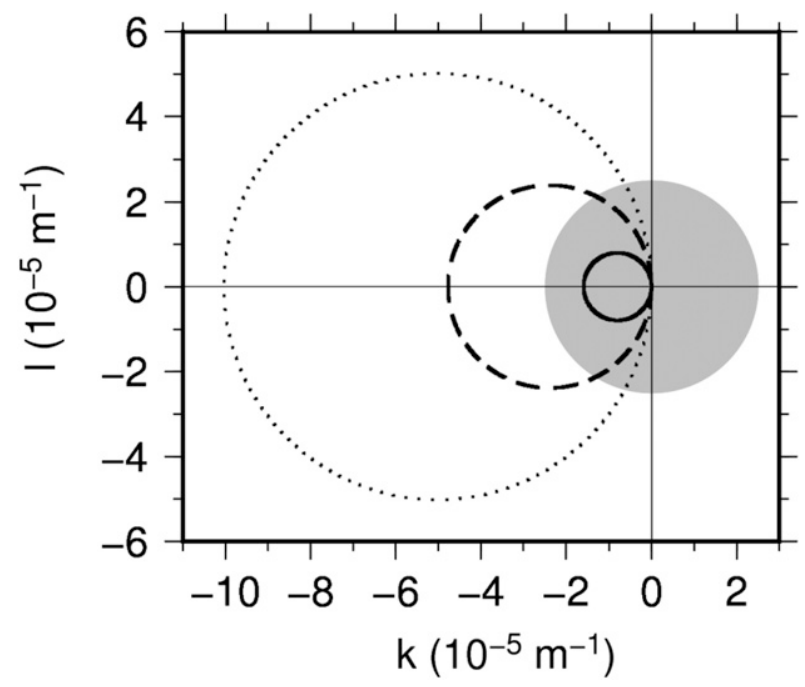

FIG. A1. Dispersion relation of barotropic Rossby waves at periods of 54 (solid circle), 174 (dashed circle), and 365 (dotted circle) days. Shaded region indicates wavenumbers smaller than $1 / L_{d}$, where $L_{d}$ is the baroclinic Rossby radius of deformation $(40 \mathrm{~km})$.

Pacific basin (Kawabe and Fujio 2010) and transmitting bottom water warming in the North Pacific (Fukasawa et al. 2004; Kawano et al. 2006; Masuda et al. 2010).

Acknowledgments. We wish to express our thanks to the cooperation of captains, crews, and onboard scientists and technicians during Shinsei-maru KS-14-7 and KS-15-14 cruises and Hakuho-maru KH-16-3 cruise, in which we conducted mooring works. We also would like to thank Shoji Kitagawa, who helped us to prepare the mooring observations. The mooring observations at TA were conducted by Keisuke Taira, Toshihiko Teramoto, and Shoji Kitagawa at the Ocean Research Institute (at present, Atmosphere and Ocean Research Institute), the University of Tokyo. Randolph Watts, Kathleen Donohue, and Karen Tracey of the University of Rhode Island gave us very insightful comments and suggested to use the velocity data obtained in KESS. The authors are grateful to Keita Iga, Toshiyuki Hibiya, Akira Masuda, Yohei Onuki, and two anonymous reviewers for their useful and insightful comments. Numerical simulations were conducted by using the $\mathrm{K}$ computer at the RIKEN Advanced Institute for Computational Science under the HPCI System Research Project (Project ID: hp130010). This study was supported by the Japan Society for Promotion of Science (KAKENHI, Challenging Exploratory Research, 26610149) and by Strategic Programs for Innovative Research Field 3 of the Ministry of Education, Culture, Sports, Science, and Technology, Japan.

\section{APPENDIX A}

\section{Relationship between TRWs and $\boldsymbol{f} / \boldsymbol{H}$ Contours}

We consider why the major axes of variance ellipses at periods of 174 days and longer tend to be parallel to $f / H$ contours under stratification. TRWs generated in meanders of the Kuroshio

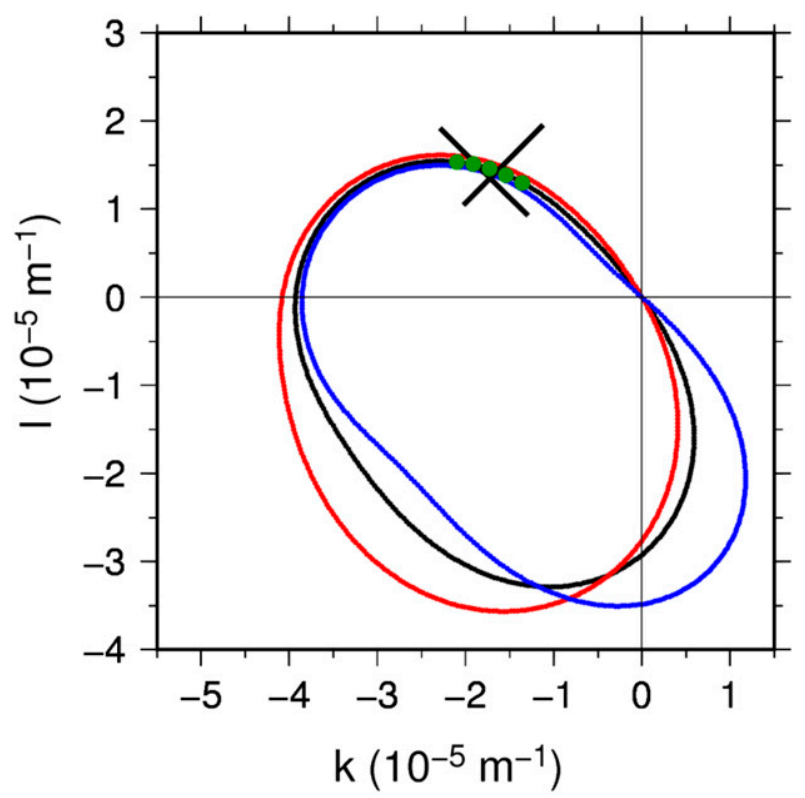

FIG. B1. The dispersion relations of TRW at a period of 174 days based on bottom topography smoothed over $1.5^{\circ} \times 1.5^{\circ}, 2^{\circ} \times 2^{\circ}$, and $3^{\circ} \times 3^{\circ}$ regional boxes (blue, black, and red curves, respectively). A cross denotes wavenumbers estimated from the phase lag for $u$ at a period of 174 days at a depth of $4000 \mathrm{~m}$ depth at M1-M9 (Fig. 9a). Center of the cross denotes averaged wavenumbers, and length of the cross indicates the minimum and maximum of estimated wavenumbers. Green dots near the cross are five initial wavenumbers of ray tracing conducted by using bottom topography smoothed over the $2^{\circ} \times 2^{\circ}$ regional box (Fig. B2).

Extension are expected to have wavenumbers comparable to or smaller than $1 / L_{d}$, where $L_{d}$ is the baroclinic Rossby radius of deformation and was estimated to be $40 \mathrm{~km}$ in the Kuroshio Extension region (Chelton et al. 1998; shaded region in Fig. A1). If we consider the dispersion circle for barotropic Rossby waves assuming that the topographic beta effect is small compared to the planetary beta effect (Fig. A1), the right-hand (left-hand) part of the circle characterized by smaller (larger) $|k|$ is considered to be longer (shorter) waves, whose velocity variability tends (does not tend) to be parallel to the zonal axis, probably corresponding to almost zonal $\mathrm{f} / \mathrm{H}$ contours over relatively flat bottom topography (Pedlosky 1987). For a period of 365 or 174 days, the shaded region in Fig. A1 contains only right-hand part of the dispersion circle, which indicates that TRWs at these periods exist only as longer waves and their velocity variability tends to be parallel to $f / H$ contours. On the other hand, for a period of 54 days, the whole dispersion circle is included in the shaded region, which means that TRWs at this period can exist both as longer and shorter waves.

\section{APPENDIX B}

\section{Robustness of Ray Tracing of TRWs}

We investigated dependence of the dispersion relation of topographic Rossby wave (TRW) under stratification (Rhines 1970) and its ray trajectories on smoothing scale of bottom 
(a)

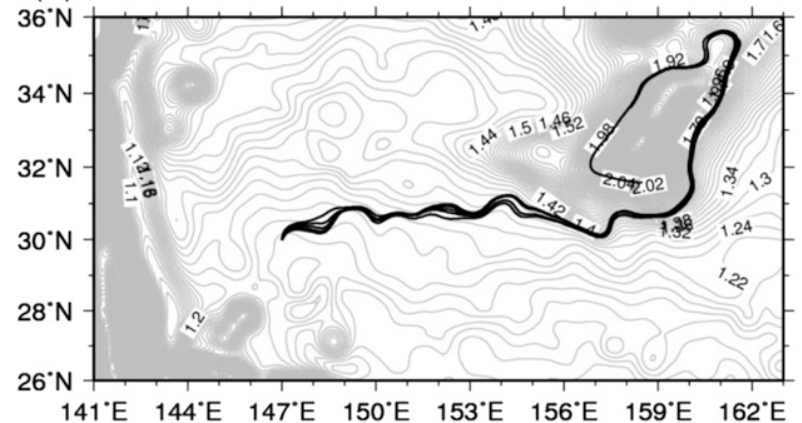

(b)

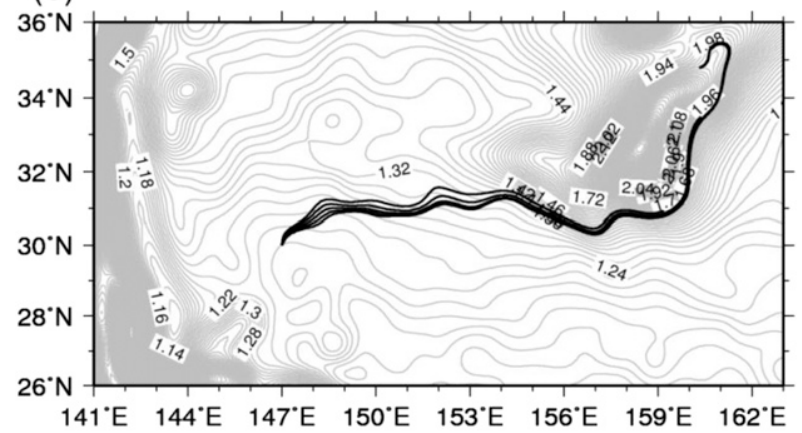

(c)

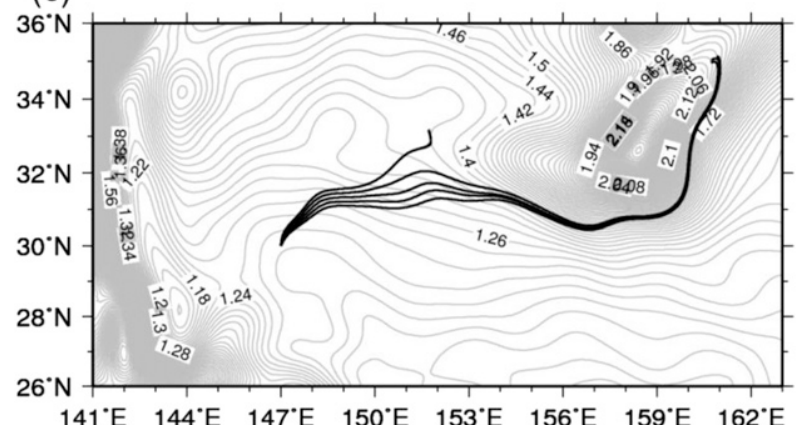

FIG. B2. Backward trajectories of five rays of TRW with different initial wavenumbers at a period of 174 days from $30.0^{\circ} \mathrm{N}, 147.0^{\circ} \mathrm{E}$ for 400 days (thick black curve). Gray contours denote $f / H$ $\left(10^{-8} \mathrm{~m}^{-1} \mathrm{~s}^{-1}\right)$ based on smoothed bottom topography. The trajectories and $\mathrm{f} / \mathrm{H}$ contours are based on bottom topography smoothed over (a) $1.5^{\circ} \times 1.5^{\circ}$, (b) $2^{\circ} \times 2^{\circ}$, and (c) $3^{\circ} \times 3^{\circ}$ regional boxes.

topography. We used $H, H_{x}$, and $H_{y}$ estimated by fitting a plane to the bottom topography (ETOPO1; Amante and Eakins 2009 ) over $1.5^{\circ} \times 1.5^{\circ}, 2^{\circ} \times 2^{\circ}$, and $3^{\circ} \times 3^{\circ}$ regional boxes with Hanning weighting. The dispersion curves of TRW at site R estimated by using the three different smoothed bottom topography were almost similar around the wavenumbers estimated from phase lags among moorings (Fig. B1). Note that the $2^{\circ} \times 2^{\circ}$ regional box is the same one in section 4 and used to investigate dependence of backward ray tracing on initial wavenumbers.

By using bottom topography smoothed over the $2^{\circ} \times 2^{\circ}$ regional box, backward ray tracing of TRW was conducted from site $\mathrm{R}$ by setting five initial wavenumbers (green dots in Fig. B1) including the same one in Fig. 17. All trajectories of the five rays indicated that energy propagated from the eastern slope of the Shatsky Rise (Fig. B2b). Similarly, by using bottom topography smoothed over the $1.5^{\circ} \times 1.5^{\circ}$ and $3^{\circ} \times 3^{\circ}$ regional boxes, backward ray tracing of TRWs was conducted from site $\mathrm{R}$ by setting five different initial wavenumbers, which satisfy the dispersion relation of TRWs based on each smoothed bottom topography. In both of the smoothed bottom topography, backward trajectories of the five rays tended to reach the eastern slope of Shatsky Rise along $f / H$ contours (Figs. B2a and B2c). Therefore, the dispersion relation of TRWs and their ray trajectories are not sensitive to the difference of smoothing scale of bottom topography and initial wavenumbers.

\section{REFERENCES}

Adcroft, A., C. Hill, and J. Marshall, 1997: Representation of topography by shaved cells in a height coordinate ocean model. Mon. Wea. Rev., 125, 2293-2315, https://doi.org/10.1175/15200493(1997)125<2293:ROTBSC > 2.0.CO;2.

Amante, C., and B. W. Eakins, 2009: ETOPO1 1 arc-minute global relief model: Procedures, data sources, and analysis. NOAA Tech. Memo. NESDIS NGDC-24, 25 pp., https://www.ngdc.noaa.gov/ $\mathrm{mgg} / \mathrm{global} / \mathrm{relief} / \mathrm{ETOPO} 1 /$ docs/ETOPO1.pdf.

Bishop, S. P., D. R. Watts, J. H. Park, and N. G. Hogg, 2012: Evidence of bottom-trapped currents in the Kuroshio Extension region. J. Phys. Oceanogr., 42, 321-328, https://doi.org/10.1175/JPO-D11-0144.1.

Bower, A. S., and N. G. Hogg, 1992: Evidence for barotropic wave radiation from the Gulf Stream. J. Phys. Oceanogr., 22, 42-61, https://doi.org/10.1175/1520-0485(1992)022<0042: EFBWRF $>2.0 . \mathrm{CO} ; 2$

—, M. S. Lozier, S. F. Gary, and C. W. Böning, 2009: Interior pathways of the North Atlantic meridional overturning circulation. Nature, 459, 243-247, https://doi.org/10.1038/nature07979.

— S. Lozier, and S. Gary, 2011: Export of Labrador Sea Water from the subpolar North Atlantic: A Lagrangian perspective. Deep-Sea Res. II, 58, 1798-1818, https://doi.org/10.1016/ j.dsr2.2010.10.060.

Charles, S., 2015: NCDI Standard Online Product: Global Ocean Currents Database (GOCD) (NCEI Accession 0093183). NOAA/National Centers for Environmental Information, accessed 2 May 2017, https://www.nodc.noaa.gov/gocd/ cmportal.html.

Chelton, D. B., and M. G. Schlax, 1996: Global observations of oceanic Rossby waves. Science, 272, 234-238, https://doi.org/ 10.1126/science.272.5259.234.

_ , R. A. Deszoeke, M. G. Schlax, K. El Naggar, and N. Siwertz, 1998: Geographical variability of the first baroclinic Rossby radius of deformation. J. Phys. Oceanogr., 28, 433-460, https://doi.org/ 10.1175/1520-0485(1998)028<0433:GVOTFB >2.0.CO;2.

- M. G. Schlax, and R. M. Samelson, 2011: Global observations of nonlinear mesoscale eddies. Prog. Oceanogr., 91, 167-216, https://doi.org/10.1016/j.pocean.2011.01.002.

Dong, C., J. C. McWilliams, Y. Liu, and D. Chen, 2014: Global heat and salt transports by eddy movement. Nat. Commun., 5, 3294, https://doi.org/10.1038/ncomms4294.

Donohue, K. A., D. R. Watts, K. L. Tracey, A. D. Greene, and M. Kennelly, 2010: Mapping circulation in the Kuroshio Extension with an array of current and pressure recording 
inverted echo sounders. J. Atmos. Oceanic Technol., 27, 507527, https://doi.org/10.1175/2009JTECHO686.1.

Ducet, N., P. Y. Le Traon, and G. Reverdin, 2000: Global highresolution mapping of ocean circulation from TOPEX/Poseidon and ERS-1 and -2. J. Geophys. Res., 105, 19477-19498, https:// doi.org/10.1029/2000JC900063.

Fukasawa, M., H. Freeland, R. Perkin, T. Watanabe, H. Uchida, and A. Nishina, 2004: Bottom water warming in the North Pacific Ocean. Nature, 427, 825-827, https://doi.org/10.1038/ nature 02337.

Gary, S. F., M. S. Lozier, C. W. Böning, and A. Biastoch, 2011: Deciphering the pathways for the deep limb of the Meridional Overturning Circulation. Deep-Sea Res. II, 58, 1781-1797, https://doi.org/10.1016/j.dsr2.2010.10.059.

Gill, A. E., and R. I. Parker, 1970: Contours of " $h \operatorname{cosec} \theta$ " for the world's ocean. Deep-Sea Res. Oceanogr. Abstr., 17, 823-824, https://doi.org/10.1016/0011-7471(70)90044-6.

Godin, G., 1972: The Analysis of Tides. Liverpool University Press, 264 pp.

Grachev, Y. M., M. N. Koshlyakov, D. A. Nechayev, T. Sazhina, and M. Yaremchuk, 1984: Dynamics of open-ocean synoptic eddies in the POLYMODE region. Oceanology, 24, 549-557.

Greene, A. D., D. R. Watts, G. G. Sutyrin, and H. Sasaki, 2012: Evidence of vertical coupling between the Kuroshio Extension and topographically controlled deep eddies. J. Mar. Res., 70, 719-747, https://doi.org/10.1357/002224012806290723.

Haidvogel, D. B., and P. B. Rhines, 1983: Waves and circulation driven by oscillatory winds in an idealized ocean basin. Geophys. Astrophys. Fluid Dyn., 25, 1-63, https://doi.org/10.1080/ 03091928308221747.

Hamilton, P., 2009: Topographic Rossby waves in the Gulf of Mexico. Prog. Oceanogr., 82, 1-31, https://doi.org/10.1016/ j.pocean.2009.04.019.

Hasumi, H., 2015: CCSR Ocean Component Model (COCO) version 4.0. Center for Climate System Research Rep. 25, 103 pp., https:// ccsr.aori.u-tokyo.ac.jp/ hasumi/COCO/coco4.pdf.

Hogg, N. G., 2000: Low-frequency variability on the western flanks of the Grand Banks. J. Mar. Res., 58, 523-545, https://doi.org/ 10.1357/002224000321511007.

— acoustic current meters. J. Phys. Oceanogr., 37, 148-161, https://doi.org/10.1175/JPO3003.1.

Holland, W. R., and P. B. Rhines, 1980: An example of eddy-induced ocean circulation. J. Phys. Oceanogr., 10, 1010-1031, https:// doi.org/10.1175/1520-0485(1980)010<1010:AEOEIO>2.0.CO;2.

Imawaki, S., 1983: Vorticity balance for mid-ocean mesoscale eddies at an abyssal depth. Nature, 303, 606-607, https:// doi.org/10.1038/303606a0.

_ 1985: Features of mesoscale eddies in the deep mid-ocean of the western North Pacific. Deep-Sea Res., 32A, 599-611, https://doi.org/10.1016/0198-0149(85)90046-9.

_ spectrum in the deep western North Pacific. Science, 216, 1407-1408, https://doi.org/10.1126/science.216.4553.1407.

— , and — 2018: Mesoscale eddies observed by moored current-meters at abyssal depths in the western North Pacific during 1978-1985. La Mer, 56, 67-94.

Kawabe, M., and S. Fujio, 2010: Pacific Ocean circulation based on observation. J. Oceanogr., 66, 389-403, https://doi.org/10.1007/ s10872-010-0034-8.

Kawano, T., M. Fukasawa, S. Kouketsu, H. Uchida, T. Doi, I. Kaneko, M. Aoyama, and W. Schneider, 2006: Bottom water warming along the pathway of lower circumpolar deep water in the Pacific Ocean. Geophys. Res. Lett., 33, L23613, https:// doi.org/10.1029/2006GL027933.

Large, W. G., and S. G. Yeager, 2009: The global climatology of an interannually varying air-sea flux data set. Climate Dyn., 33, 341-364, https://doi.org/10.1007/s00382-008-0441-3.

Lozier, M. S., S. F. Gary, and A. S. Bower, 2013: Simulated pathways of the overflow waters in the North Atlantic: Subpolar to subtropical export. Deep-Sea Res. II, 85, 147-153, https:// doi.org/10.1016/J.DSR2.2012.07.037.

Malanotte-Rizzoli, P., N. G. Hogg, and R. E. Young, 1995: Stochastic wave radiation by the Gulf Stream: Numerical experiments. Deep-Sea Res. I, 42, 389-423, https://doi.org/ 10.1016/0967-0637(95)00001-M.

Masuda, S., and Coauthors, 2010: Simulated rapid warming of abyssal North Pacific waters. Science, 329, 319-322, https:// doi.org/10.1126/science.1188703.

McWilliams, J. C., and G. R. Flierl, 1976: Optimal, quasi-geostrophic wave analyses of MODE array data. Deep-Sea Res. Oceanogr. Abstr., 23, 285-300, https://doi.org/10.1016/0011-7471(76)90871-8.

Miyamoto, M., E. Oka, D. Yanagimoto, S. Fujio, G. Mizuta, S. Imawaki, M. Kurogi, and H. Hasumi, 2017: Characteristics and mechanism of deep mesoscale variability south of the Kuroshio Extension. Deep-Sea Res. I, 123, 110-117, https:// doi.org/10.1016/j.dsr.2017.04.003.

MODE Group, 1978: The mid-ocean dynamics experiment. Deep-Sea Res., 25, 859-910, https://doi.org/10.1016/0146-6291(78)90632-X.

Oey, L. Y., and H. C. Lee, 2002: Deep eddy energy and topographic Rossby waves in the Gulf of Mexico. J. Phys. Oceanogr., 32, 3499-3527, https://doi.org/10.1175/1520-0485(2002)032<3499: DEEATR $>2.0 . \mathrm{CO} ; 2$.

Pedlosky, J., 1987: Geophysical Fluid Dynamics. 2nd ed. SpringerVerlag, 710 pp.

Pickart, R. S., 1995: Gulf Stream-generated topographic Rossby waves. J. Phys. Oceanogr., 25, 574-586, https://doi.org/10.1175/ 1520-0485(1995)025<0574:GSTRW >2.0.CO;2.

— variability at Cape Hatteras. J. Mar. Res., 48, 765-791, https:// doi.org/10.1357/002224090784988674.

Price, J. F., and H. T. Rossby, 1982: Observations of a barotropic planetary wave in the western North Atlantic. J. Mar. Res., 40, 543-558.

Rhines, P. B., 1969: Slow oscillations in an ocean of varying depth Part 1. Abrupt topography. J. Fluid Mech., 37, 161-189, https:// doi.org/10.1017/S0022112069000474.

- 1970: Edge-, bottom-, and Rossby waves in a rotating stratified fluid. Geophys. Fluid Dyn., 1, 273-302, https://doi.org/ 10.1080/03091927009365776.

Robinson, A. R., 1983: Eddies in Marine Science. Springer-Verlag, 609 pp.

Roemmich, D., and J. Gilson, 2001: Eddy transport of heat and thermocline waters in the North Pacific: A key to interannual/decadal climate variability? J. Phys. Oceanogr., 31, 675-687, https://doi.org/ 10.1175/1520-0485(2001)031<0675:ETOHAT>2.0.CO;2.

Rossby, T., D. Dorson, and J. Fontaine, 1986: The RAFOS system. J. Atmos. Oceanic Technol., 3, 672-679, https://doi.org/10.1175/ 1520-0426(1986)003<0672:TRS > 2.0.CO;2.

Schmitz, W. J., Jr., 1988: Exploration of the eddy field in the midlatitude North Pacific. J. Phys. Oceanogr., 18, 459-468, https://doi.org/ 10.1175/1520-0485(1988)018<0459:EOTEFI > 2.0.CO;2.

—, P. P. Niiler, R. L. Bernstein, and W. R. Holland, 1982: Recent long-term moored instrument observations in the western North Pacific. J. Geophys. Res., 87, 9425-9440, https://doi.org/ 10.1029/JC087iC12p09425. 
and C. J. Koblinsky, 1987: Two-year moored instrument results along $152^{\circ} \mathrm{E}$. J. Geophys. Res., 92, 10 826-10834, https://doi.org/10.1029/JC092iC10p10826.

Steele, M., R. Morley, and W. Ermold, 2001: PHC: A global ocean hydrography with a high-quality Arctic Ocean. J. Climate, 14, 2079-2087, https://doi.org/10.1175/1520-0442(2001)014<2079: PAGOHW $>2.0 . \mathrm{CO} ; 2$.

Stommel, H., 1958: The abyssal circulation. Deep-Sea Res., 5, 8082, https://doi.org/10.1016/S0146-6291(58)80014-4.

- , and A. B. Arons, 1960a: On the abyssal circulation of the world ocean-I. Stationary planetary flow patterns on a sphere. Deep-Sea Res., 6, 140-154, https://doi.org/10.1016/ 0146-6313(59)90065-6.

- and 1960b: On the abyssal circulation of the world ocean-II. An idealized model of the circulation pattern and amplitude in oceanic basins. Deep-Sea Res., 6, 217-233, https:// doi.org/10.1016/0146-6313(59)90075-9.

Thompson, R. O., and J. R. Luyten, 1976: Evidence for bottomtrapped topographic Rossby waves from single moorings.
Deep-Sea Res. Oceanogr. Abstr., 23, 629-635, https://doi.org/ 10.1016/0011-7471(76)90005-X.

Thomson, R. E., and W. J. Emery, 2014: Data Analysis Methods in Physical Oceanography. 3rd ed. Elsevier, 716 pp.

Tracey, K. L., D. R. Watts, K. A. Donohue, and H. Ichikawa, 2012: Propagation of Kuroshio Extension meanders between $143^{\circ}$ and $149^{\circ}$ E. J. Phys. Oceanogr., 42, 581-601, https://doi.org/ 10.1175/JPO-D-11-0138.1.

Waterman, S., and S. R. Jayne, 2012: Eddy-driven recirculations from a localized transient forcing. J. Phys. Oceanogr., 42, 430447, https://doi.org/10.1175/JPO-D-11-060.1.

Watts, D. R., M. A. Kennelly, K. A. Donohue, K. L. Tracey, T. K. Chereskin, R. A. Weller, and I. Victoria, 2013: Four current meter models compared in strong currents in Drake Passage. J. Atmos. Oceanic Technol., 30, 2465-2477, https://doi.org/ 10.1175/JTECH-D-13-00032.1.

Zhang, Z., W. Wang, and B. Qiu, 2014: Oceanic mass transport by mesoscale eddies. Science, 345, 322-324, https://doi.org/10.1126/ science. 1252418 . 